\title{
Fabrication of calixarene-grafted bio-polymeric magnetic composites for magnetic solid phase extraction of non- steroidal anti-inflammatory drugs in water samples
}

\author{
Syed Fariq Fathullah Syed Yaacob ${ }^{1}$, Arniza Khairani Mohd Jamil ${ }^{1}$, Muhammad Afzal Kamboh ${ }^{2}$, Wan Aini Wan \\ Ibrahim ${ }^{3}$, Sharifah Mohamad Corresp. 1,4 \\ 1 Department of Chemistry, Faculty of Science, Universiti Malaya, Kuala Lumpur, Malaysia \\ 3 Separation Science and Technology Group (SepSTec), Department of Chemistry, Faculty of Science, Universiti Teknologi Malaysia, Johor Bahru, Johor, \\ Malaysia \\ 4 Universiti Malaya Centre for Ionic Liquids, Universiti Malaya, Kuala Lumpur, Malaysia \\ Corresponding Author: Sharifah Mohamad \\ Email address: sharifahm@um.edu.my
}

Calixarene framework functionalized bio-polymeric magnetic composites (MSp-TDI-calix) were synthesized and utilized as magnetic solid-phase extraction (MSPE) sorbent for the extraction of non-steroidal anti-inflammatory drugs (NSAIDs), namely indoprofen (INP), ketoprofen (KTP), ibuprofen (IBP) and fenoprofen (FNP), from environmental water samples. MSp-TDI-calix was characterized by FT-IR, XRD, FESEM, EDX, VSM and BET analysis, and the results were compared with Sp-TDI and Sp-TDI-calix. To maximize the extraction performance of MSp-TDI-calix decisive MSPE affective parameters such as sorbent amount, extraction time, sample volume, type of organic eluent, volume of organic eluent, desorption time and pH were comprehensively optimized prior to HPLCDAD determination. The analytical validity of the proposed MSPE method was evaluated under optimized conditions and the following figures of merit were acquired: linearity with good determination coefficient $\left(R^{2} \geq 0.991\right)$ over the concentration range of $0.5-500 \mu \mathrm{g} / \mathrm{L}$, limits of detection (LODs) ranged from $0.06-0.26 \mu \mathrm{g} / \mathrm{L}$ and limits of quantitation (LOQ) between $0.20-0.89 \mu \mathrm{g} / \mathrm{L}$. Excellent reproducibility and repeatability under harsh environment with inter-day and intra-day relative standard deviations were obtained in the range of $2.5-3.2 \%$ and $2.4-3.9 \%$ respectively. The proposed method was successfully applied for analysis of NSAIDs in tap water, drinking water and river water with recovery efficiency ranging from $88.1-115.8 \%$ with \%RSD of $1.6-4.6 \%$. 


\section{Manuscript to be reviewed}

FABRICATION OF CALIXARENE-GRAFTED BIO-POLYMERIC MAGNETIC

\section{COMPOSITES FOR MAGNETIC SOLID PHASE EXTRACTION OF NON-} STEROIDAL ANTI-INFLAMMATORY DRUGS IN WATER SAMPLES

Syed Fariq Fathullah Syed Yaacob ${ }^{1}$, Arniza Khairani Mohd Jamil ${ }^{1}$, Muhammad Afzal

${ }^{1}$ Department of Chemistry, Faculty of Science, Universiti Malaya, Kuala Lumpur, Malaysia

${ }^{2}$ Department of Chemistry, Shaheed Benazir Bhutto University, Shaheed Benazirabad, Sindh, 8 Pakistan

${ }^{3}$ Separation Science and Technology Group (SepSTec), Department of Chemistry, Faculty of Science, Universiti Teknologi Malaysia, Johor Bahru, Johor, Malaysia

$11{ }^{4}$ Universiti Malaya Centre for Ionic Liquids (UMCiL), University of Malaya, Kuala Lumpur, Malaysia

*Corresponding author: Sharifah Mohamad

14 Email:sharifahm@um.edu.my

15 Postal Address: Department of Chemistry, Faculty of Science, University of Malaya, 50603

16 Kuala Lumpur, MALAYSIA

17 Phone Number: (+6)0379676751; Fax: $(+6) 0379674193$

\section{ABSTRACT}

22 Calixarene framework functionalized bio-polymeric magnetic composites (MSp-TDI-calix) were synthesized and utilized as magnetic solid-phase extraction (MSPE) sorbent for the

24 extraction of non-steroidal anti-inflammatory drugs (NSAIDs), namely indoprofen (INP),

25 ketoprofen (KTP), ibuprofen (IBP) and fenoprofen (FNP), from environmental water 
samples. MSp-TDI-calix was characterized by FT-IR, XRD, FESEM, EDX, VSM and BET

27 analysis, and the results were compared with Sp-TDI and Sp-TDI-calix. To maximize the extraction performance of MSp-TDI-calix decisive MSPE affective parameters such as sorbent amount, extraction time, sample volume, type of organic eluent, volume of organic

30 eluent, desorption time and $\mathrm{pH}$ were comprehensively optimized prior to HPLC-DAD

31 determination. The analytical validity of the proposed MSPE method was evaluated under optimized conditions and the following figures of merit were acquired: linearity with good determination coefficient $\left(R^{2} \geq 0.991\right)$ over the concentration range of $0.5-500 \mu \mathrm{g} / \mathrm{L}$, limits of detection (LODs) ranged from $0.06-0.26 \mu \mathrm{g} / \mathrm{L}$ and limits of quantitation (LOQ) between $0.20-0.89 \mu \mathrm{g} / \mathrm{L}$. Excellent reproducibility and repeatability under harsh environment with inter-day and intra-day relative standard deviations were obtained in the range of $2.5-3.2 \%$ and $2.4-3.9 \%$ respectively. The proposed method was successfully applied for analysis of NSAIDs in tap water, drinking water and river water with recovery efficiency ranging from $88.1-115.8 \%$ with $\%$ RSD of $1.6-4.6 \%$.

\section{INTRODUCTION}

43 From an environmental point of view, the mixing of pharmaceuticals as well as their degraded products into natural streams is of great concern (Lacey et al., 2008; Toledo-Neira \& Álvarez-Lueje, 2015). Recent reports indicated that drugs from pharmaceutical waste have long-term adverse effects to humans and the aquatic system (Van Hoeck et al., 2009; AguilarArteaga et al., 2010). Non-steroidal anti-inflammatory drugs (NSAIDs) is one of the most important group of pharmaceutical drugs to treat pain and inflammation. These compounds inhibit the production of cyclooxygenase enzymes and reduce the prostaglandins level that causes pain, inflammation and fever within the human body (Fan et al., 2014; Amiri et al., 2016). Overdose of NSAIDs generally cause adverse side effects such as ulcers, kidney 
52 failure and stomach bleeding which can ultimately lead to sudden death. These side effects

53 are more prominent towards those with poor health conditions and alcoholics (Shukri et al.,

54 2015). The NSAIDs may transfer to natural streams through hospital and pharmaceutical

55 units effluent, as well as private household manure (Toledo-Neira \& Álvarez-Lueje, 2015).

56 These drugs pose toxic effects in aquatic ecosystems and may cause harm not only to marine

57 life but also to humans (Aguilar-Arteaga et al., 2010). Consequently, the precise

58 determination of NSAIDs is of prime importance. Pharmaceutical compounds are mainly

59 present in water samples at trace levels (Luo et al., 2014). It is a challenge to reach down to

60 this detection level due to complicated matrix effects in real samples and thus needs to be

61 adequately addressed. Several analytical techniques such as gas chromatography

62 (GC),(Samaras et al., 2011) capillary electrophoresis (CE),(Macià et al., 2004) liquid

63 chromatography mass spectrometry (LC-MS)(Toledo-Neira \& Álvarez-Lueje, 2015) and high

64 performance liquid chromatography (HPLC) (Aguilar-Arteaga et al., 2010) have been

65 employed for NSAIDs determination. Comparatively, due to high resolution, great

66 automation and high reproducibility, HPLC is considered as one of the most commonly used

67 technique (Fan et al., 2014).

69 Various sample preparation methods have been reported for the enrichment and purification

70 of pharmaceutical compounds. Liquid-liquid extraction (LLE) (Wen, Tu \& Lee, 2004; Payán

71 et al., 2009), solid phase extraction (SPE) (Santos et al., 2005; Rodil et al., 2009), stir rod

72 sorptive extraction (SRSE) (Luo et al., 2011), dispersive liquid-liquid microextraction

73 (DLLME) (Shukri et al., 2015), and solid phase micro-extraction (SPME) (Moeder et al.,

74 2000; Torres Padrón, Sosa Ferrera \& Santana Rodríguez, 2009) methods are commonly used

75 for determination of drugs and their metabolites. Among these techniques, solid phase

76 extraction is one of the most virtual and reliable method due to its advantages of producing 
77 high enrichment factors, magnificent selectivity and high recovery (Li \& Lee, 2001).

78 However, the classical SPE method has disadvantages such as solvent loss, time

consumption, large secondary waste, expensive complex equipment and tedious procedure

80 (Asgharinezhad et al., 2014). Magnetic solid phase extraction (MSPE) was developed as an

81 alternative method to the SPE procedure due to its spectacular characteristics which can overcome the limitations of SPE. Simple procedure, economical, high efficiency, rapidity, less consumption of organic solvent and no filtration and/or centrifugation required for sample preparation are some benefits of MSPE (Wang et al., 2013; Wan Ibrahim et al., 2015).

To acquire adequate recovery of target analytes, appropriate sorbent selection is essential in

MSPE procedures. Iron oxide such as magnetite $\left(\mathrm{Fe}_{3} \mathrm{O}_{4}\right)$ is an example of magnetic nanoparticles (MNPs) that is widely used as a sorbent because of its high surface area, economical value, low toxicity, simple preparation steps and easy separation of target analytes from samples (Rossi, Quach \& Rosenzweig, 2004; Tahmasebi \& Yamini, 2012). The use of MNPs significantly decrease the extraction period to enable the balance between solid phase and analytes and also reduce the consumption of sorbent mass even with large volumes of samples (Wierucka \& Biziuk, 2014). However, naked MNPs are instable in acidic medium, easily oxidize, agglomerate in aqueous solution and lack selectivity ( $\mathrm{Xu}$ et al., 2014). Thus, various approaches can be adopted to modify the surface of MNPs via

96 functionalization or immobilization in order to overcome these limitations. One such

97 approach is the modification of MNPs with a bio-polymeric material known as sporopollenin as a potential robust sorbent (Kaya et al., 2016). Sporopollenin forms the tough spore/pollen wall of a land plant known as "Lycopodium clavatum". The aromatic rings of sporopollenin contains carbon, hydrogen and oxygen with the stoichiometry formula of $\mathrm{C}_{90} \mathrm{H}_{144} \mathrm{O}_{27}$

101 (Kamboh et al., 2016). The superior properties of sporopollenin are its resistance towards 
102 harsh chemicals, high thermal stability, stable against mineral acid and alkaline and possess

103 excellent physical and chemical strength (Crini \& Ndongo Peindy, 2006; Ayar, Gezici \&

104 Küçükosmanoğlu, 2007). Apart from that, sporopollenin is also economical, ecological and

105 readily accessible (Barrier et al., 2011; Mundargi et al., 2016). Thus, sporopollenin is a

106 potential bio-polymer material sorbent for MNPs modification by functionalizing the

107 sporopollenin surface with suitable functional groups for extraction of target analytes.

108 Furthermore, the inner and outer surface of sporopollenin is available for binding with guest

109 molecule due to its $2 \mu \mathrm{m}$ thick perforated walls hollowed exine which makes it porous

110 (Kamboh et al., 2016). The MNPs can easily embed on the surface of sporopollenin due to

111 the availability of large internal cavity of exine, allowing it to be easily magnetized by MNPs.

113 Calixarenes is a remarkable macrocyclic host compound that can be synthesized by the

114 oligomerization of phenol and formaldehyde (Demirkol et al., 2014; Gokoglan et al., 2015).

115 The outstanding properties possessed by calixarenes makes its inner cavity surface

116 hydrophobic as well as outer surface hydrophilic which can be tuned structurally to achieve

117 desired properties (Kamboh et al., 2016). Calixarenes can form host guest inclusion complex

118 with a variety of guest compounds such as ions, amino acid and metal ions by

119 functionalization of the upper or lower rim of the molecule. Hence, calixarenes can be

120 extensively used as a trapping agent to encapsulate target compounds through host-guest

121 interactions. By combining calixarene modified magnetic nanoparticles and sporopollenin as

122 solid support, herein we introduce the novel nanocomposite for extraction of NSAIDs from

123 water samples. Based on reported literature, the preparation of calixarene modified magnetic

124 nanoparticles mostly involves tedious and lengthy preparation procedures ( $\sim 40$ days of

125 reflux) (Gubbuk et al., 2012; Sayin, Ozcan \& Yilmaz, 2013; Kamboh et al., 2016). Hence,

126 we aim to initiate a simpler and shorter $(<10$ hours $)$ synthesis procedure and easier 


\section{Manuscript to be reviewed}

127 preparation of the sorbent. Other than that, using less organic solvent for preparation of the

128 calixarene modified magnetic nanoparticles compared to reported publications would be a

129 crucial factor in preserving the environment towards a greener research (Sayin \& Yilmaz,

130 2011).

131

132 In this study, a bio-polymeric material sorbent modified with $p$-tert-butylcalix[4]arene was

133 employed to extract and detect NSAIDs in water samples. The sorbent surface was also

134 magnetized with MNPs to ease separation using an external magnetic field. The role of host

135 guest encapsulation of calixarene makes it a suitable host candidate to entrap and extract the

136 NSAIDs from environmental samples by applying MSPE technique. In addition, the

137 hydrogen bonding, $\pi-\pi$ interaction and hydrophobic interaction that could be formed with

138 NSAIDs would allow the modified nanocomposite to selectively entrap and bind the NSAIDs

139 at the surface.The NSAIDs group namely INP, KTP, IBP and FNP as illustrated in Fig. 1

140 were selected as analytes because of their frequent consumption as drugs in Malaysia based

141 on Anatomical Therapeutic Chemical (ATC) report (Khairudin et al., 2017). Hence, the

142 occurrence probability of these NSAIDs in water samples is very high due to its high

143 consumption among the Malaysian population (Khairudin et al., 2017).

145 MATERIALS AND METHODS

146 Materials

147 "Lycopodium clavatum" sporopollenin (25 $\mu \mathrm{m}$ particle size), toluene-2,4-diisocyanate (TDI)

148 (CAS no 584-84-9) was purchased from Sigma-Aldrich (Steinheim, Germany). Indoprofen

149 (CAS no. 34842-01-0), ibuprofen (CAS no. 15687-27-1) and fenoprofen (CAS no. 53746-45-

150 5) were purchased from Sigma-Aldrich (Steinheim, Germany). Ketoprofen (CAT no.

151 155154) was purchased form MP Biomedicals Inc. (Ohio, USA). HPLC-grade acetonitrile 


\section{Manuscript to be reviewed}

152 was provided by Merck (Dermstadt, Germany) and HPLC-grade acetic acid was provided by

153 J.T Baker Avantor Performance Material Inc. (PA, USA). Analytical grade ammonia,

154 dichloromethane, ethanol, $n$-hexane, toluene, chloroform, ethyl acetate, dimethylformamide,

155 hydrochloric acid and sodium hydroxide pellet were purchased from Merck (Darmstadt,

156 Germany) and used without further purification. Dry toluene and dry N,N-

157 dimethylformamide (DMF) were obtained from Merck (Dermstadt, Germany). Ferrous

158 chloride tetrahydrate (CAS no. 13478-10-9) and ferric chloride hexahydrate (CAS no. 10025-

159 77-1) were obtained from Sigma-Aldrich (Steinheim, Germany). Analytical grade methanol

160 used for the preparation of standard working solutions was obtained from Merck (Dermstadt,

161 Germany). The $\mathrm{pH}$ of the solution was adjusted by mixing appropriate volume of $0.1 \mathrm{M}$

162 hydrochloric acid $(\mathrm{HCl})$ and/or sodium hydroxide $(\mathrm{NaOH})$. Deionized water that had been

163 passed through a Milli-Q system (Lane End, UK) was used during the preparation of

164 solutions. Deionized water was filtered through a $0.22 \mu \mathrm{m}$ nylon filter (Whatman, England)

165 for preparing the mobile phase solvent before being added with $1 \%$ acetic acid. The $p$-tert-

166 butylcalix[4]arene was synthesized according to previously reported method (Gutsche, Iqbal

$167 \&$ Stewart, 1986).

168

169 Standard solutions

170 Stock solutions of NSAIDs were prepared in methanol and stored at $2{ }^{\circ} \mathrm{C}$ in the refrigerator.

171 The stock solutions were prepared fresh monthly due to their stability. The working solutions

172 were prepared daily by dilution from stock solution with a final concentration of $1 \mathrm{mg} / \mathrm{L}$

173 using the same solvent as the stock solution. Calibration curve $(n=7)$ was prepared by serial

174 dilution of the mixed working solution in deionized water and performing MSPE procedure

175 as described below. The resulting individual concentrations ranged from $0.5-500 \mu \mathrm{g} / \mathrm{L}(0.5$,

$1761,5,10,50,100,500 \mu \mathrm{g} / \mathrm{L})$. The samples were injected into the HPLC system under 
177 optimized conditions and the chromatogram was recorded at multiple wavelengths

178 respectively. Each measurement was done in triplicates.

179

180 Quantification and method validation

181 Method validation was carried out in terms of linearity, precision, limit of detection (LOD),

182 and limit of quantification (LOQ). The linearity of the method was measured at seven

183 concentrations from 0.5 to $500 \mu \mathrm{g} / \mathrm{L}$ as described earlier. The calibration curves were plotted

184 by peak area as the $\mathrm{y}$-axis versus concentration as the $\mathrm{x}$-axis and the linear regression

185 equations were calculated for each analyte. The precision was expressed in relative standard

186 deviation (RSD) and evaluated in terms of intra-day (repeatability) and inter-day

187 (reproducibility). Intra-day was assessed by performing five replicate analyses on single day

$188(\mathrm{n}=5)$ and inter-day (reproducibility) was carried out by performing five replicates on three

189 consecutive days $(\mathrm{n}=15)$. LOD was determined based on the signal-to-noise ratio and is

190 defined mathematically as equal to three times the standard deviation of the blank $(3 \mathrm{SD} / \mathrm{m})$

191 and LOQ is ten times the standard deviation of the blank $(10 \mathrm{SD} / m)$ where SD is the standard

192 deviation from ten injections of blank samples $(n=10)$ and $m$ is the gradient slope from the

193 calibration curve.

195 Instruments

196 The Fourier transform-infrared spectroscopy (FT-IR) spectrum was obtained using ATR

197 mode on a Spectrum 400 Perkin Elmer in the range of $4000-450 \mathrm{~cm}^{-1}$ with diamond as the

198 detector. X-ray diffraction (XRD) patterns of the samples were taken using PANalytical

199 Empyrean X-ray diffractometer (EA Almelo, The Netherlands) from $2 \Theta=15^{\circ}$ to $75^{\circ}$ at room

200 temperature utilizing $\mathrm{Cu} \mathrm{K} \alpha$ radiation at a wavelength of $1.5418 \AA$ at a scan rate of $0.02 \mathrm{~s}^{-1}$.

201 Field emission scanning electron microscopy with energy dispersive X-ray spectroscopy 
202 (FESEM-EDX) analysis was performed by using the HITACHI SU8220 scanning electronic

203 microscopy from OXFORD Instrument (Oxfordshire, UK). The magnetization of

204 functionalized MNP was measured using a vibrating sample magnetometer (VSM LakeShore

2057400 series). The surface area and porosity were measured using Brunauer-Emmett-Teller

206 (BET) by nitrogen adsorption-desorption isotherm in Micromeritics Tristar II ASAP 2020,

207 (GA, USA). HPLC system (Kyoto, Japan) based on LC-20AT pump, SPD-M20A diode array

208 detector, SIL-20A HT autosampler and CTO-10AS VP column oven was used for NSAIDs

209 determination. The system was equipped with a Hypersil gold C-18 reverse phase column

$210(250 \times 4.6 \mathrm{~mm})$, particle size $(5 \mu \mathrm{m})$ from ThermoScience (MA, USA).

211

212 HPLC parameters and conditions

213 HPLC-DAD system was used for the chromatographic identification of selected NSAIDs

214 from the water samples. Chromatographic separation of the selected NSAIDs were carried

215 out using acidified (1\% with acetic acid) water/acetonitrile $(50: 50 \mathrm{v} / \mathrm{v})$ as the mobile phase at

216 a flow rate of $1.0 \mathrm{~mL} \mathrm{~min}^{-1}$. The HPLC column temperature was set at $40{ }^{\circ} \mathrm{C}$. The sample

217 injection volume was $10 \mu \mathrm{L}$. The DAD detection for the selected NSAIDs was carried out at

218 multiple wavelengths i.e., 281, 255, 271 and $219 \mathrm{~nm}$ for INP, KTP, IBP and FNP

219 respectively.

220

221 Synthesis

222 Preparation of sporopollenin containing active site (Sp-TDI) (1)

$2232.0 \mathrm{~g}$ of sporopollenin and $10 \mathrm{~mL}$ of toluene-2,4-diisocyanate (TDI) were mixed with the help

224 of a magnetic stirrer in $20 \mathrm{~mL}$ dry toluene. The functionalization was performed under

225 nitrogen gas at room temperature for $4 \mathrm{hrs}$. Then, the resultant Sp-TDI was separated by 
226 centrifugation at $2000 \mathrm{rcf}$ for $5 \mathrm{~min}$ and sequentially washed with dry toluene. The sample

227 was dried and stored in a desiccator.

228

229

Preparation of p-tert-butylcalix[4]arene based sporopollenin (Sp-TDI-calix) (2)

$230 \quad 0.411 \mathrm{~g}$ of $p$-tert-butylcalix[4]arene was dissolved in $20 \mathrm{~mL}$ of dry $\mathrm{N}, \mathrm{N}$-dimethylformamide

231 (DMF) followed by the addition of $1.5 \mathrm{~g}$ of Sp-TDI (l) and stirred at $70{ }^{\circ} \mathrm{C}$ for $2 \mathrm{hrs}$ using a

232 magnetic stirrer in the presence of nitrogen gas. The resultant compound was washed with

233 dichloromethane (DCM) and deionized water for the removal of unnecessary particles

234 absorbed on the sample surface. The sample was dried and stored in a desiccator and labelled

235 as Sp-TDI-calix (2).

236

237

Preparation of magnetic p-tert-butylcalix[4]arene based sporopollenin (MSp-TDI-calix) (3)

238 The magnetization of $p$-tert-butylcalix[4]arene functionalized TDI modified sporopollenin

239 (Sp-TDI-calix) (3) was carried out as follows; $13.3 \mathrm{~g}$ of $\mathrm{FeCl}_{3} \cdot 6 \mathrm{H}_{2} \mathrm{O}, 19.9 \mathrm{~g}$ of $\mathrm{FeCl}_{2} .4 \mathrm{H}_{2} \mathrm{O}, 5$

$240 \mathrm{~mL}$ of $\mathrm{HCl}(5 \mathrm{M}), 40 \mathrm{~mL}$ of deionized water and $5 \mathrm{~mL}$ of ethanol were mixed in a flask

241 followed by heating to $40{ }^{\circ} \mathrm{C}$ until complete dissolution of the salts occured. Then, $1.0 \mathrm{~g}$ of

242 Sp-TDI-calix (2) was re-dispersed in $30 \mathrm{~mL}$ of the solution and stirred for $2 \mathrm{~h}$ at room

243 temperature. The Sp-TDI-calix (3) suspension was filtered and the filtrate was quickly

244 washed with deionized water and immediately transferred into $0.1 \mathrm{M}$ ammonia solution.

245 After $2 \mathrm{~h}$ stirring at room temperature, the resultant compound was separated from the

246 solution using an external magnet, washed thoroughly with deionized water and dried under

247 vacuum. Fig. 2 illustrates the synthesis pathway of the MSp-TDI-calix (3) sorbent.

248

249 Magnetic solid phase extraction (MSPE) 


\section{Manuscript to be reviewed}

250 For the MSPE technique, $30 \mathrm{mg}$ of MSp-TDI-calix (3) sorbent was added to $200 \mathrm{~mL}$ of

251 spiked sample which contained a mixture of $1 \mu \mathrm{g} / \mathrm{L}$ INP, KTP, IBP and FNP respectively in

252 deionized water at $\mathrm{pH}$ 4. The solution was horizontally shaken using a shaker for $30 \mathrm{~min}$ to

253 allow the sorbent to disperse uniformly in the solution. Then, neodymium (Nd) magnet was

254 used to isolate the sorbent from the solution. The solution became limpid after a few minutes

255 and the upper solution was decanted. Afterwards, $1.5 \mathrm{~mL}$ of acetonitrile was added to elute

256 the NSAIDs adsorbed on MSp-TDI-calix (3) and horizontally shaken for another $30 \mathrm{~min}$. The

257 collected eluate was dried using a stream of nitrogen gas and re-dissolved in $0.7 \mathrm{~mL}$ of

258 acetonitrile. Finally, $10 \mu \mathrm{L}$ portion of the eluate was injected into HPLC for analysis.

259

260 Real sample preparation

261 Different types of water samples i.e tap water, drinking water and river water was utilized to

262 check the matrix effects towards extraction of NSAIDs. Tap water was obtained from the

263 analytical chemistry laboratory in University of Malaya, Malaysia. Drinking water was

264 purchased from a local store. River water was collected from Sungai Sendat, Selangor,

265 Malaysia. The samples were stored at $4{ }^{\circ} \mathrm{C}$ prior to use.

266

\section{RESULTS AND DISCUSSIONS}

268 Characterization of sorbent

269 The chemical structure of the synthesized sorbent was characterized using FT-IR, XRD,

270 FESEM-EDX, BET and VSM analyses. Fig. 3 depicts the IR of Sp-TDI, Sp-TDI-calix and

271 MSp-TDI-calix. In Sp-TDI, the presence of IR bands at $2280 \mathrm{~cm}^{-1}$ may be attributed to the

272 isocyanate peak while appearance of the IR band at $1645 \mathrm{~cm}^{-1}$ confirmed the existence of

273 aromatic rings. The IR bands at $1604 \mathrm{~cm}^{-1}$ and $1233 \mathrm{~cm}^{-1}$ indicates the presence of $\mathrm{C}=\mathrm{O}$ and

274 C-N stretches of the formed carbamate linkages between isocyanate proving the 


\section{Manuscript to be reviewed}

275 incorporation of isocyanate functionalities on the surface of sporopollenin. Meanwhile, the

276 disappearance of reserved isocyanate peak in Sp-TDI-calix is due to the functionalization

277 between Sp-TDI surface with $p$-tert-butylcalix[4]arene. Hence, the absence of the peak at

$2782280 \mathrm{~cm}^{-1}$ indicates that $p$-tert-butylcalix[4]arene was successfully bonded onto the surface of

279 the Sp-TDI. Moreover, the appearance of bands at $1677 \mathrm{~cm}^{-1}, 1454 \mathrm{~cm}^{-1}$ and $1200 \mathrm{~cm}^{-1}$

280 correspond to $\mathrm{C}_{\mathrm{Ar}}-\mathrm{C}_{\mathrm{Ar}}$ stretching, methylene bridge $-\mathrm{CH}_{2}$ - and $\mathrm{C}-\mathrm{C}$ stretching respectively

281 proving that $p$-tert-butylcalix[4] arene has been grafted on the surface of sporopollenin.

282 Finally, IR bands at $566 \mathrm{~cm}^{-1}$ are associated with the magnetite $\mathrm{Fe}_{3}-\mathrm{O}_{4}$ band in MSp-TDI-

283 calix which indicates that the sorbent was successfully magnetized with MNPs.

285 The surface morphology of the sorbent was analysed with FESEM. The FESEM images of raw sporopollenin, Sp-TDI-calix and MSp-TDI-calix are depicted in Fig. 4. The image of raw sporopollenin in Fig. 4A shows a smooth morphology with an open and uniform interconnected hexagonal hollowed structure surface. Meanwhile, the FESEM image for SpTDI-calix in Fig. 4B shows the pores of sporopollenin changed to rough and lumpy filled with $p$-tert-butylcalix[4]arene particles. Fig. $4 \mathrm{C}$ clearly shows that $\mathrm{Fe}_{3} \mathrm{O}_{4}$ particles were filled inside the hollow surface of sporopollenin and each hollow structure remained unchanged after the magnetization process. Hence, these images reveal that the functionalization process of $p$-tert-butylcalix[4]arene onto the surface of sporopollenin was successful and magnetite has also embedded inside the pores of sporopollenin.

Energy dispersive X-ray spectroscopy (EDX) analysis gave promising results in terms of elemental composition. Fig. 5A and Fig. 5B represents the FESEM image and EDX spectra with the elemental composition of Sp-TDI-calix and MSp-TDI-calix respectively. As stated 
300 Sp-TDI-calix showed $14.4 \%$ nitrogen which originates from the isocyanate group after

301 immobilization with $p$-tert-butylcalix[4]arene. Meanwhile, after the magnetization process

302 with $\mathrm{Fe}_{3} \mathrm{O}_{4}$, EDX detected $33.8 \%$ iron present in MSp-TDI-calix indicating that the final

303 material MSp-TDI-calix was successfully filled with MNP

304

305 The XRD analyses were conducted to determine the crystallinity of Sp-TDI, Sp-TDI-calix, and MSp-TDI-calix. As represented in supplemental information Fig. S1A, Sp-TDI exhibits

307 broad diffraction peaks at $\sim 25^{\circ}$ which are typically observed for amorphous materials.

308 Meanwhile, a few diffraction peaks appeared at $\sim 10^{\circ}-30^{\circ}$ when $p$-tert-butylcalix[4]arene

309 was functionalized on the surface of Sp-TDI. The additional peaks, as displayed in Fig. S1B

310 indicate that $p$-tert-butylcalix[4]arene improved the crystallinity of Sp-TDI-calix. In

311 conformity with the Joint Committee on Powder Diffraction Standards (JCPDS) reference

312 pattern of magnetite (00-019-0629), six diffraction peaks of $\mathrm{Fe}_{3} \mathrm{O}_{4}$ were observed in MSp-

313 TDI-calix in Fig. S1C which are 220, 311, 400, 422, 511, and 440. These peaks are related to

314 cubic spine plane of $\mathrm{Fe}_{3} \mathrm{O}_{4}$ and thus confirmed the presence of $\mathrm{Fe}_{3} \mathrm{O}_{4}$. It is also observed that

315 no distinct diffraction peaks of $p$-tert-butylcalix[4]arene appeared for MSp-TDI-calix which

316 indicate that the $p$-tert-butylcalix[4]arene molecules were homogeneously distributed.

318 VSM technique was used to measure the strength of magnetization behaviour of MSp-TDI-

319 calix. As shown in Fig. S2 (supplemental information), MSp-TDI-calix sample displayed

320 typical superparamagnetic behaviour. The saturation magnetizations of the sample was 19.4

$321 \mathrm{emu} / \mathrm{g}$ and sufficient for magnetic separation since the reported minimal magnetic strength

322 for separation is $16.3 \mathrm{emu} / \mathrm{g}$ (Cho et al., 2015). This data proved that the prepared sorbent

323 could be dispersed in water and separated by using neodymium magnet. The inset photos in

324 Fig. S2 shows the sorbent separation using external magnetic field. 


\section{Manuscript to be reviewed}

325

326 Fig. S3 (supplemental information) shows the nitrogen adsorption-desorption isotherm of the

327 sorbent MSp-TDI-calix. It exhibit close to type IV as defined by the IUPAC classification

328 with an evident hysteresis loop in the range of $0.05-1.0$ and suggests that the sorbent is

329 basically a mesoporous material (Farhadi, Safabakhsh \& Zaringhadam, 2013). The specific

330 surface area of the sample calculated by the BET is $26.5 \mathrm{~m}^{2} \mathrm{~g}^{-1}$. Moreover, the pore size can

331 be calculated from the surface area according to the equation $4 \mathrm{~V} / \mathrm{S}_{\mathrm{BET}}$, where $\mathrm{V}$ is adsorption

332 total pore volume and $\mathrm{S}_{\mathrm{BET}}$ is the specific surface area of the MSp-TDI-calix. The pore size

333 calculated from the surface area data is approximately $18.8 \mathrm{~nm}$. Table S1 (supplemental

334 information) summarizes the pore size, pore volume and $\mathrm{S}_{\mathrm{BET}}$ value for sporopollenin, $\mathrm{Sp}$ -

335 TDI-calix and MSp-TDI-calix. The lower BET surface area in Sp-TDI-calix in comparison to 336 raw sporopollenin from $2.24 \mathrm{~m}^{2} / \mathrm{g}-2.08 \mathrm{~m}^{2} / \mathrm{g}$ could be due to the adsorption sites being

337 covered by $p$-tert-butylcalix[4]arene which have immobilized on the surface of Sp-TDI,

338 hindering the $\mathrm{N}_{2}$ molecules from accessing the binding site. Thus, it showed that the $p$-tert-

339 butylcalix[4]arene was successfully bonded to the Sp-TDI surface (Huang et al., 2010). The

340 surface area, pore volume and pore size of the sorbent increased due to dispersity of the

341 particles, and therefore, enhanced the adsorption capacity especially for large adsorbate

342 molecules (Fan et al., 2011).

344 Optimization of MSPE

345 Herein, the prepared bio-polymer sorbent MSp-TDI-calix were used as MSPE sorbent to

346 evaluate the extraction of target analytes namely INP, KTP, IBP and FNP from the NSAIDs

347 group. In order to achieve optimal conditions for the MSPE procedure, various parameters

348 including sorbent amount, extraction time, sample volume, type of organic eluent, volume of

349 organic eluent, desorption time and sample solution $\mathrm{pH}$ were investigated. 


\section{Manuscript to be reviewed}

350

351

Sorbent amount

352 Sorbent amount is the most important parameter to improve the recovery of target analytes.

353 Different amounts of sorbent ranging from 5 to $50 \mathrm{mg}$ were evaluated to determine the

354 extraction efficiency. As shown in Fig. 6A, peak area increased with increasing amounts of

355 sorbent up to $30 \mathrm{mg}$ due to availability of accessible sites for interaction. Increasing the

356 sorbent amount increases the adsorption active sites and thus leads to higher peak areas

357 (Rashidi Nodeh et al., 2017). However, above $30 \mathrm{mg}$ sorbent amount, the peak area showed a

358 slightly decreasing trend because of the weak elution by a fixed volume of the eluent towards

359 the adsorbed analytes (Tahmasebi \& Yamini, 2014). The fixed volume of the eluent solvent

360 was insufficient to achieve a complete dissolution of the sorbent (Arghavani-Beydokhti,

361 Rajabi \& Asghari, 2018). The larger sorbent amount at definite volume and specific contact

362 time possibly decreased the elution efficiency and thus reduced the peak area obtained

363 (Shahriman et al., 2018). Moreover, the loss of sorbent amount during separation process by

364 an external magnet may have also lead to a decrease in peak areas (Bagheri, Roostaie \&

365 Baktash, 2014). Thus, $30 \mathrm{mg}$ was chosen to extract targeted NSAIDs from aqueous samples

366 for all subsequent experiments.

368 Sample volume

369 Sample volume plays an important role in recovering the target analytes. High enrichment

370 factor and high sensitivity can be obtained by using a large sample volume (Soutoudehnia

371 Korrani et al., 2016). Thus, six different volume of water samples ranging from 20 to $250 \mathrm{~mL}$

372 were studied. As shown in Fig. 6B, the highest peak area was obtained with $200 \mathrm{~mL}$ sample

373 volume. However, beyond $200 \mathrm{~mL}$ sample volume, the peak area decreased for KTP

374 especially probably due to the breakthrough volume being exceeded (Abd Rahim et al., 
375 2016). The recovery of INP, IBP and FNP did not increase significantly when $250 \mathrm{~mL}$

376 sample loading volume was used. Therefore, $200 \mathrm{~mL}$ of sample volume was selected as

377 optimum volume for further extraction of NSAIDs in water samples.

378

379 Extraction and desorption time

380 The extraction and desorption time profiles was obtained by varying the time between $5-60$

381 min. Based on the results shown in Fig. 7A, it is evident that the maximum peak area was

382 obtained at an extraction time of $30 \mathrm{~min}$ and a further increase in extraction time lowered the

383 extraction recovery. Meanwhile, for the desorption process, $10 \mathrm{~min}$ was adequate to elute all

384 target analytes from the sorbent surface as shown in Fig. 7B. Since MSPE is a dynamic

385 process, after 30 min of extraction process and desorption the analytes may be destroyed

386 when the process period is prolonged (Xue, Li \& Xu, 2017). Hence, the extraction and

387 desorption efficiency decreased at longer time periods. It can be concluded that 30 min of

388 extraction and 10 min of desorption time were sufficient for further experiments.

390 Type of organic eluent and volume

391 Seven types of organic solvents, namely methanol, acetonitrile, $n$-hexane, toluene,

392 chloroform, ethyl acetate, dichloromethane and dimethylformamide were used as desorption

393 solvents to examine their role towards the extraction efficiencies of studied NSAIDs. As

394 shown in Fig. 8A, acetonitrile showed the best result to desorb NSAIDs with an overall high

395 recovery compared to other organic solvents. These phenomena can be explained by the

396 molecular interaction between the analytes and the sorbent surface. The intermolecular forces

397 that may occur between MSp-TDI-calix and NSAIDs are hydrogen bonding, dipole-dipole

398 interaction, $\pi-\pi$ interaction and van der waals forces. The organic eluent disrupts the retentive

399 intermolecular forces between sorbent surface and analyte. Methanol is expected to give a 
400 strong eluent effect on polar polymeric sorbents, but acetonitrile gives excellent eluent effect

401 on sorbent surface compared with methanol. This is because methanol has a strong polar

402 eluent strength and is unable to disrupt non-polar interaction sites. Acetonitrile has mid to

403 polar-apolar eluent strength that can disrupt the binding mechanism at polar and non-polar

404 site sorbent surfaces. Nonpolar solvents such as $n$-hexane has poor eluent capability due to its

405 non-polar characteristic to disrupt the polar interaction. Effects due to volume of the organic

406 eluent was also determined. As presented in Fig. 8B, six different volumes ranging from 0.5

407 to $3.0 \mathrm{~mL}$ of acetonitrile were optimized. The maximum peak area was observed with $1.5 \mathrm{~mL}$

408 volume of acetonitrile. In contrast, above $1.5 \mathrm{~mL}$ of acetonitrile, the peak area decreased due

409 to dilution factor and loss of analytes to environment at higher volume of organic eluent

410 (Shukri et al., 2015; Hu et al., 2017; Rashidi Nodeh et al., 2017). During drying the elution

411 extract by nitrogen gas stream, the higher volume needed more time to dry and

412 preconcentrate the analytes. Thus, some of analytes may be loss to the surroundings during

413 this period and caused a decrease in peak area. Therefore, $1.5 \mathrm{~mL}$ of acetonitrile was selected

414 to be utilized in further experiments.

415

416 Solution $\mathrm{pH}$

417 The $\mathrm{pH}$ condition plays an important role on the extraction efficiency of analytes as changes

418 in $\mathrm{pH}$ can influence the charges on both the sorbent and analytes. As clearly shown in Fig. 9,

419 the extraction of NSAIDs is $\mathrm{pH}$ dependent. It is obvious that the peak area increased from $\mathrm{pH}$

4202 to $\mathrm{pH} 4$ and decreased as the $\mathrm{pH}$ value increased further from $\mathrm{pH} 6$ to $\mathrm{pH} 12$. This

421 observation is related to the $\mathrm{pK}_{\mathrm{a}}$ value of the selected NSAIDs. Most of the NSAIDs have a

$422 \mathrm{pK}_{\mathrm{a}}$ value in the range of $3.66-4.88$. At $\mathrm{pH}<\mathrm{pK}_{\mathrm{a}}$ value, NSAIDs mostly exist in their

423 neutral form, which leads to the formation of intermolecular forces such as hydrogen

424 bonding, $\pi-\pi$ interaction and hydrophobic interaction between MSp-TDI-calix and the target 


\section{Manuscript to be reviewed}

425 NSAIDs. Therefore, highest extraction efficiency was achieved below $\mathrm{pH} 4.88$. In the case

426 whereby $\mathrm{pH}>\mathrm{pK}_{\mathrm{a}}$ value, ionization process takes place and the NSAIDs transform to their

427 anion form, severely weakening the existing intermolecular forces (Luo et al., 2011; Fan et

428 al., 2014). As a result, the extraction efficiency of target analytes decreased. Therefore, $\mathrm{pH}$

4294.0 was selected as the optimum $\mathrm{pH}$ for subsequent analysis of NSAIDs. In addition, the

430 designed nanocomposite performing well under acidic conditions also indicates the suitability

431 of sporopollenin as a solid support for MNPs in overcoming the instability of the naked

432 MNPs in acidic medium.

433

434 Reusability of the sorbent

435 Recycling of sorbents is crucial for practical applications to improve cost effectiveness. Fig.

436 S4 (supplemental information) displays the efficiency of MSp-TDI-calix sorbent for

437 extraction of selected NSAIDs when regenerated up to 5 cycles. The sorbent was washed

438 with acetonitrile before proceeding to subsequent MSPE applications. The recovery

439 efficiency showed stability even after 5 extractions, with $80 \%$ efficiency from the first cycle.

440 Thus, the MSp-TDI-calix magnetic particles are mechanically stable and possesses good

441 reusability.

442

443 Method validation

444 Optimal conditions for extraction of selected NSAIDs using the proposed MSPE method 445 were $30 \mathrm{mg}$ sorbent amount, $200 \mathrm{~mL}$ sample volume, 30 min extraction and $10 \mathrm{~min}$ 446 desorption time, $1.5 \mathrm{~mL}$ acetonitrile as organic eluent and $\mathrm{pH} 4$ of sample solution. Linearity,

447 LOD, LOQ and precision (intra-day and inter-day) were evaluated to validate the studied

448 method under these optimal conditions. As listed in Table 1, all tested NSAIDs showed good

449 linearity with good coefficient of determination $\left(R^{2} \geq 0.991\right)$. LOD was calculated based on 


\section{Manuscript to be reviewed}

450 signal-to-noise ratio $(3 \mathrm{xD} / m)(n=10)$ and the values obtained was in the range of 0.07 to

$4510.26 \mu \mathrm{g} / \mathrm{L}$. Meanwhile, LOQ with signal-to-noise ratio $(10 \times \mathrm{SD} / m)(n=10)$ was also

452 evaluated and the values obtained was in the range of $0.2-0.89 \mu \mathrm{g} / \mathrm{L}$. Precision was studied

453 in terms of repeatability (intra-day), $(n=5)$ and reproducibility (inter-day), $(n=15)$ and

454 expressed as relative standard deviation (RSD). The intra-day precision was demonstrated by

455 performing five replicates of standard solutions on a single day. The inter-day precision of

456 the MSPE procedure was evaluated by performing standard solutions of the same

457 concentration levels in five replicates on three consecutive days. The results showed that the

458 intra-day and inter-day RSDs were in the range of $2.4-3.9 \%$ and $2.5-3.2 \%$ respectively.

459 Results obtained for the LOD, LOQ and repeatability precision as shown in Table 1 indicate

460 that the method had high sensitivity and repeatability.

461

462 Environmental water samples analysis

463 The proposed MSPE method using MSp-TDI-calix sorbent for extraction of selected NSAIDs

464 was applied to the analysis of three different types of environmental water samples (tap

465 water, drinking water and river water). In order to determine the effect of sample matrix, the

466 real samples were spiked with four NSAIDs; INP, KTP, IBP and FNP at the concentration of

$46710 \mu \mathrm{g} / \mathrm{L}$ and $100 \mu \mathrm{g} / \mathrm{L}$ under optimized conditions. Fig. 10 displays the chromatogram of

468 spiked water samples containing $10 \mu \mathrm{g} / \mathrm{L}$ of NSAIDs compared with non-spiked samples.

469 The results which are tabulated in Table 2 shows satisfactory recovery of NSAIDs in tap water ranging from $88.1 \%-110.7 \%$ with RSDs $(n=5)$ in the range of $1.6 \%-4.6 \%$. For drinking water, the recovery achieved range between $91.9 \%-107.9 \%$ with RSDs $(n=5)$

472 from $1.9 \%-4.6 \%$. Meanwhile, NSAIDs recovery in river water samples showed excellent 473 recovery in the range of $94.3 \%-115.8 \%$ with RSDs $(n=5)$ from $1.8 \%-4.5 \%$. Based on the

474 results obtained, the good recoveries of the selected NSAIDs in the three different sample 
475 matrices at trace levels shows the high potential of this MSPE technique. However, no

476 analyte in the non-spiked real samples were detected.

477

\section{Comparative study}

479 The efficiency of the proposed MSp-TDI-calix was compared with similar MSPE methods 480 reported in the literature. Table 3 summarizes several sorbents used for the determination of 481 NSAIDs using MSPE method in different matrices in terms of linearity, LOD, and recovery. 482 As can been seen, this work achieved excellent recovery, lower LODs as well as improved 483 sensitivity compared with other reported methods. The LOD achieved by the present work is 484 lower compared to other research studies using the MSPE method. These results demonstrate 485 the great potential of the proposed method for analysis of NSAIDs in water samples.

\section{CONCLUSIONS}

488 The extraction of NSAIDs on magnetic bio-polymer grafted with $p$-tert-butylcalix[4]arene 489 (MSp-TDI-calix) utilizing the MSPE technique was studied. The synthesized material was successfully grafted and proved with various instruments including spectroscopy, morphology, elementary, magnetic behaviour and thermal characterization analyses. The new sorbent in combination with HPLC-DAD enable sensitive analysis of selected NSAIDs in environment sample matrices such as tap water, drinking water and river water at low levels.

494 The extraction of selected NSAIDs gave acceptable and low LOD values in the range of 0.06 $495-0.26 \mu \mathrm{g} / \mathrm{L}$ and high recovery rates ranging from $88.1-115.8 \%$ for tested real samples.

496 These advantages together with the effective regeneration and stability of the sorbent indicate 497 its applicability to be employed as an alternative sorbent for enrichment and preconcentration 498 of NSAIDs in environmental sample matrices. 
500 ACKNOWLEDGEMENTS

501 The authors are grateful to administrative authorities at the Department of Chemistry, UM.

502 Special thanks go to Mrs. Ruhaida Bahru, the Sr. Asst. Science Officers and Mr. Nor Affandi

503 Tamar, Asst. Science Officers at the Environmental Research Laboratory for their kind

504 support in the analysis work. Help rendered by the UM postgraduate students-Siti Khalijah

505 Mahmad Rozi and Ahmad Razali Ishak was invaluable. 


\section{Manuscript to be reviewed}

\section{REFERENCES}

507 Abd Rahim M., Wan Ibrahim WA., Ramli Z., Sanagi MM., Aboul-Enein HY. 2016. New

508 sol-gel hybrid material in solid phase extraction combined with liquid chromatography

509 for the determination of non-steroidal anti-inflammatory drugs in water samples.

$510 \quad$ Chromatographia 79:421-429.

511 Aguilar-Arteaga K., Rodriguez JA., Miranda JM., Medina J., Barrado E. 2010. Determination

512 of non-steroidal anti-inflammatory drugs in wastewaters by magnetic matrix solid phase

513 dispersion-HPLC. Talanta 80:1152-1157.

514 Amiri M., YadollahYamini., Safari M., Asiabi H. 2016. Magnetite nanoparticles coated with

515 covalently immobilized ionic liquids as a sorbent for extraction of non-steroidal anti-

516 inflammatory drugs from biological fluids. Microchimica Acta 183:2297-2305.

517 Arghavani-Beydokhti S., Rajabi M., Asghari A. 2018. Coupling of two centrifugeless

518 ultrasound-assisted dispersive solid/liquid phase microextractions as a highly selective,

519 clean, and efficient method for determination of ultra-trace amounts of non-steroidal

520 anti-inflammatory drugs in complicated matrices. Analytica Chimica Acta 997:67-79.

521 Asgharinezhad AA., Mollazadeh N., Ebrahimzadeh H., Mirbabaei F., Shekari N. 2014.

522 Magnetic nanoparticles based dispersive micro-solid-phase extraction as a novel

523 technique for coextraction of acidic and basic drugs from biological fluids and waste

$524 \quad$ water. Journal of Chromatography A 1338:1-8.

525 Ayar A., Gezici O., Küçükosmanoğlu M. 2007. Adsorptive removal of methylene blue and 526 methyl orange from aqueous media by carboxylated diaminoethane sporopollenin: On the usability of an aminocarboxilic acid functionality-bearing solid-stationary phase in column techniques. Journal of Hazardous Materials 146:186-193.

529 Bagheri H., Roostaie A., Baktash MY. 2014. A chitosan-polypyrrole magnetic nanocomposite as $\mu$-sorbent for isolation of naproxen. Analytica Chimica Acta 816:1-7. 


\section{Manuscript to be reviewed}

531 Barrier S., Diego-Taboada A., Thomasson MJ., Madden L., Pointon JC., Wadhawan JD., Beckett ST., Atkin SL., Mackenzie G. 2011. Viability of plant spore exine capsules for microencapsulation. J. Mater. Chem. 21:975-981.

534 Cha YB., Myung S. 2013. Determination of Non-Steroidal Anti-Inflammatory Drugs in Human Urine Sample using HPLC / UV and Three Phase Hollow Fiber-Liquid Phase Microextraction. Bulletin of the Korean Chemical Society 34:3444-3450.

Cho E., Tahir MN., Choi JM., Kim H., Yu JH., Jung S. 2015. Novel magnetic nanoparticles coated by benzene- and $\beta$-cyclodextrin-bearing dextran, and the sorption of polycyclic aromatic hydrocarbon. Carbohydrate Polymers 133:221-228.

Crini G., Ndongo Peindy H. 2006. Adsorption of C.I. Basic Blue 9 on cyclodextrin-based material containing carboxylic groups. Dyes and Pigments 70:204-211.

Demirkol DO., Yildiz HB., Sayin S., Yilmaz M. 2014. Enzyme immobilization in biosensor constructions: self-assembled monolayers of calixarenes containing thiols. RSC $A d v$. 4:19900-19907. DOI: 10.1039/C3RA47642A.

Fan W., Mao X., He M., Chen B., Hu B. 2014. Development of novel sol-gel coatings by chemically bonded ionic liquids for stir bar sorptive extraction-application for the determination of NSAIDS in real samples. Analytical and Bioanalytical Chemistry

Farhadi S., Safabakhsh J., Zaringhadam P. 2013. Synthesis, characterization, and

Fan J., Zhang J., Zhang C., Ren L., Shi Q. 2011. Adsorption of 2,4,6-trichlorophenol from 406:7261-7273. investigation of optical and magnetic properties of cobalt oxide $\left(\mathrm{Co}_{3} \mathrm{O}_{4}\right)$ nanoparticles.

555 Gokoglan TC., Soylemez S., Kesik M., Unay H., Sayin S., Yildiz HB., Cirpan A., Toppare L. 
2015. A novel architecture based on a conducting polymer and calixarene derivative: Its synthesis and biosensor construction. RSC Advances 5:35940-35947.

558 Gubbuk IH., Gürfidan L., Erdemir S., Yilmaz M. 2012. Surface modification of sporopollenin with calixarene derivative: Characterization and application for metal removal. Water, Air, and Soil Pollution 223:2623-2632.

561 Gutsche CD., Iqbal M., Stewart D. 1986. Calixarenes. 18. Synthesis Procedures for p -tert Butylcalix[4]arene. Journal of Organic Chemistry 51:742-745.

Van Hoeck E., Canale F., Cordero C., Compernolle S., Bicchi C., Sandra P. 2009. Multiresidue screening of endocrine-disrupting chemicals and pharmaceuticals in aqueous samples by multi-stir bar sorptive extraction-single desorption-capillary gas chromatography/mass spectrometry. Analytical and Bioanalytical Chemistry 393:907-

Hu K., Qiao Y., Deng Z., Wu M., Liu W. 2017. SPE-UHPLC-FLD Method for the Simultaneous Determination of Five Anthraquinones in Human Urine Using MixedMode Bis ( tetraoxacalix [2 ] arene [ 2 ] triazine ) Modified Silica as Sorbent. Journal of Analytical Methods in Chemistry 2017.

Kamboh MA., Ibrahim WAW., Nodeh HR., Sanagi MM., Sherazi STH. 2016. The removal of organophosphorus pesticides from water using a new amino-substituted calixarenebased magnetic sporopollenin. New J. Chem. 40:3130-3138. hydrophobicity, and mechanical, antifungal and antioxidant properties of chitosan films. 
Journal of Industrial and Engineering Chemistry 47:236-245.

582 Khairudin KA., Jatau AI., Manan MM., Tiong CS. 2017. Utilization pattern of non-steroidal anti-inflammatory drugs at a primary health care in Malaysia. Indian Journal of Pharmaceutical Education and Research 51:156-161. DOI: 10.5530/ijper.5.

Khoeini Sharifabadi M., Saber-Tehrani M., Waqif Husain S., Mehdinia A., AberoomandAzar P. 2014. Determination of residual nonsteroidal anti-inflammatory drugs in aqueous sample using magnetic nanoparticles modified with cetyltrimethylammonium bromide by high performance liquid chromatography. Scientific World Journal 2014. method for the determination of pharmaceutical compounds in wastewater treatment plant influent and effluent samples. Talanta 75:1089-1097.

Li N., Lee HK. 2001. Solid-phase extraction of polycyclic aromatic hydrocarbons in surface water. Negative effect of humic acid. Journal of Chromatography. A 921:255-263.

Luo Y., Guo W., Ngo HH., Nghiem LD., Hai FI., Zhang J., Liang S., Wang XC. 2014. A review on the occurrence of micropollutants in the aquatic environment and their fate water-dispersible hydrophobic magnetic nanoparticles for use in solid phase extraction of non-steroidal anti-inflammatory drugs. Microchimica Acta 182:2585-2591.

604 Macià A., Borrull F., Aguilar C., Calull M. 2004. Application of capillary electrophoresis 605 with different sample stacking strategies for the determination of a group of nonsteroidal 
anti-inflammatory drugs in the low $\mu \mathrm{g} \cdot \mathrm{L}^{-1}$ concentration range. Electrophoresis 25:428-

607 436.

608

Moeder M., Schrader S., Winkler M., Popp P. 2000. Solid-phase microextraction-gas chromatography-mass spectrometry of biologically active substances in water samples. Journal of Chromatography A 873:95-106.

611 Mundargi RC., Tan EL., Seo J., Cho NJ. 2016. Encapsulation and controlled release 612 formulations of 5-fluorouracil from natural Lycopodium clavatum spores. Journal of $613 \quad$ Industrial and Engineering Chemistry 36:102-108.

614 Payán MR., López MÁB., Fernández-Torres R., Bernal JLP., Mochón MC. 2009. HPLC 615 determination of ibuprofen, diclofenac and salicylic acid using hollow fiber-based liquid phase microextraction (HF-LPME). Analytica Chimica Acta 653:184-190.

617 Rashidi Nodeh H., Wan Ibrahim WA., Kamboh MA., Sanagi MM. 2017. New magnetic graphene-based inorganic-organic sol-gel hybrid nanocomposite for simultaneous analysis of polar and non-polar organophosphorus pesticides from water samples using solid-phase extraction. Chemosphere 166:21-30.

Rodil R., Quintana JB., López-Mahía P., Muniategui-Lorenzo S., Prada-Rodríguez D. 2009. Multi-residue analytical method for the determination of emerging pollutants in water by solid-phase extraction and liquid chromatography-tandem mass spectrometry. Journal of Chromatography A 1216:2958-2969.

Rossi LM., Quach AD., Rosenzweig Z. 2004. Glucose oxidase-magnetite nanoparticle bioconjugate for glucose sensing. Analytical and Bioanalytical Chemistry 380:606-613. spectrometry. Analytical and Bioanalytical Chemistry 399:2549-2561. 
631 Santos JL., Aparicio I., Alonso E., Callejón M. 2005. Simultaneous determination of

632 pharmaceutically active compounds in wastewater samples by solid phase extraction and

633 high-performance liquid chromatography with diode array and fluorescence detectors.

$634 \quad$ Analytica Chimica Acta 550:116-122.

635 Sayin S., Ozcan F., Yilmaz M. 2013. Two novel calixarene functionalized iron oxide 636 magnetite nanoparticles as a platform for magnetic separation in the liquid-liquid/solid637 liquid extraction of oxyanions. Materials Science and Engineering C 33:2433-2439.

638 Sayin S., Yilmaz M. 2011. Synthesis of a new calixarene derivative and its immobilization 639 onto magnetic nanoparticle surfaces for excellent extractants toward $\mathrm{Cr}(\mathrm{VI}), \mathrm{As}(\mathrm{V})$, and 640 U(VI). Journal of Chemical and Engineering Data 56:2020-2029.

641 Shahriman MS., Ramachandran MR., Zain NNM., Mohamad S., Manan NSA., Yaman SM. 642 2018. Polyaniline-dicationic ionic liquid coated with magnetic nanoparticles composite 643 for magnetic solid phase extraction of polycyclic aromatic hydrocarbons in 644 environmental samples. Talanta 178:211-221.

645 Shukri DSM., Sanagi MM., Ibrahim WAW., Abidin NNZ., Aboul-Enein HY. 2015. Liquid 646 chromatographic determination of NSAIDs in urine after dispersive liquid-liquid microextraction based on solidification of floating organic droplets. Chromatographia

649 Soutoudehnia Korrani Z., Wan Ibrahim WA., Rashidi Nodeh H., Aboul-Enein HY., Sanagi MM. 2016. Simultaneous preconcentration of polar and non-polar organophosphorus pesticides from water samples by using a new sorbent based on mesoporous silica. Journal of Separation Science 39:1144-1151.

Tahmasebi E., Yamini Y. 2012. Facile synthesis of new nano sorbent for magnetic solidphase extraction by self assembling of bis-(2,4,4-trimethyl pentyl)-dithiophosphinic acid on $\mathrm{Fe}_{3} \mathrm{O}_{4} @ \mathrm{Ag}$ core@shell nanoparticles: Characterization and application. Analytica 


\section{Manuscript to be reviewed}

656

Chimica Acta 756:13-22.

657 Tahmasebi E., Yamini Y. 2014. Polythiophene-coated $\mathrm{Fe}_{3} \mathrm{O}_{4}$ nanoparticles as a selective 658

660 Toledo-Neira C., Álvarez-Lueje A. 2015. Ionic liquids for improving the extraction of 661 662

663

664 Torres Padrón ME., Sosa Ferrera Z., Santana Rodríguez JJ. 2009. Coupling of solid-phase 665 666 667 adsorbent for magnetic solid-phase extraction of silver(I), gold(III), copper(II) and palladium(II). Microchimica Acta 181:543-551. NSAIDs in water samples using dispersive liquid-liquid microextraction by high performance liquid chromatography-diode array-fluorescence detection. Talanta $134: 619-626$.

microextraction with micellar desorption and high performance liquid chromatography for the determination of pharmaceutical residues in environmental liquid samples. Biomedical Chromatography 23:1175-1185.

Wan Ibrahim WA., Nodeh HR., Aboul-Enein HY., Sanagi MM. 2015. Magnetic solid-phase extraction based on modified ferum oxides for enrichment, preconcentration, and isolation of pesticides and selected pollutants. Critical reviews in Analytical Chemistry / CRC 45:270-87.

Wang T., Liu S., Gao G., Zhao P., Lu N., Lun X., Hou X. 2017. Magnetic solid phase extraction of non-steroidal anti-inflammatory drugs from water samples using a metal organic framework of type $\mathrm{Fe}_{3} \mathrm{O}_{4} / \mathrm{MIL}-101(\mathrm{Cr})$, and their quantitation by UPLCMS/MS. Microchimica Acta 184:2981-2990.

Wang W., Ma R., Wu Q., Wang C., Wang Z. 2013. Magnetic microsphere-confined graphene for the extraction of polycyclic aromatic hydrocarbons from environmental water samples coupled with high performance liquid chromatography-fluorescence analysis. Journal of Chromatography A 1293:20-27.

Wen X., Tu C., Lee HK. 2004. Two-step liquid-liquid-liquid microextraction of nonsteroidal 
681 antiinflammatory drugs in wastewater. Analytical Chemistry 76:228-232.

682 Wierucka M., Biziuk M. 2014. Application of magnetic nanoparticles for magnetic solid683 phase extraction in preparing biological, environmental and food samples. $\operatorname{Tr} A C$ $684 \quad$ Trends in Analytical Chemistry 59:50-58.

685 Xu J., Sun J., Wang Y., Sheng J., Wang F., Sun M. 2014. Application of iron magnetic 686 nanoparticles in protein immobilization. Molecules 19:11465-11486.

687 Xue S-W., Li J., Xu L. 2017. Preparation of magnetic melamine-formaldehyde resin and its 688 application to extract nonsteroidal anti-inflammatory drugs. Analytical and 689 Bioanalytical Chemistry. 
Figure 1

The chemical structures of the selected NSAIDs

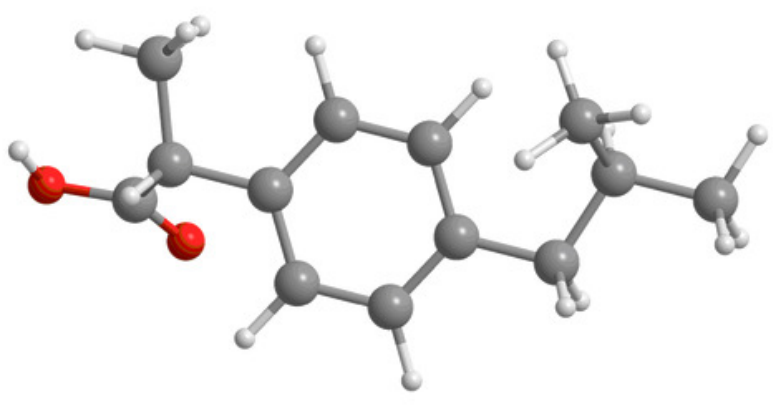

Ibuprofen $\left(\mathrm{pK}_{\mathrm{a}}=4.51\right)^{\mathrm{a}}$

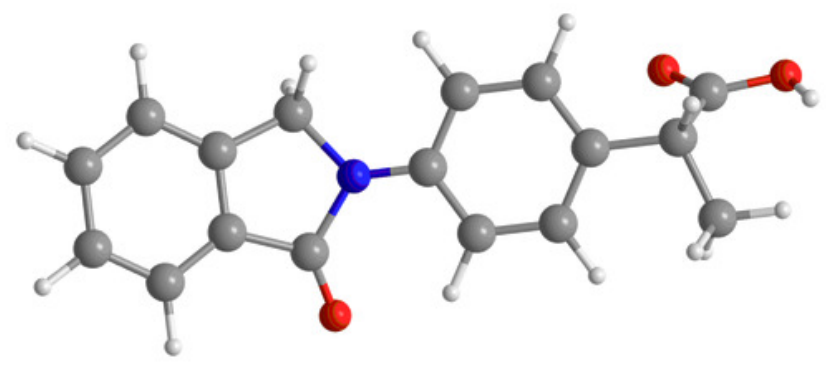

Indoprofen $\left(\mathrm{pK}_{\mathrm{a}}=4.4\right)^{\mathrm{a}}$

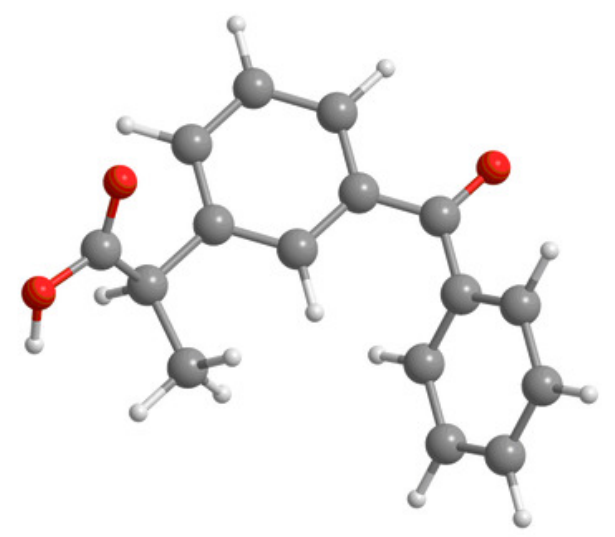

Ketoprofen $\left(\mathrm{pK}_{\mathrm{a}}=4.2\right)^{\mathrm{a}}$

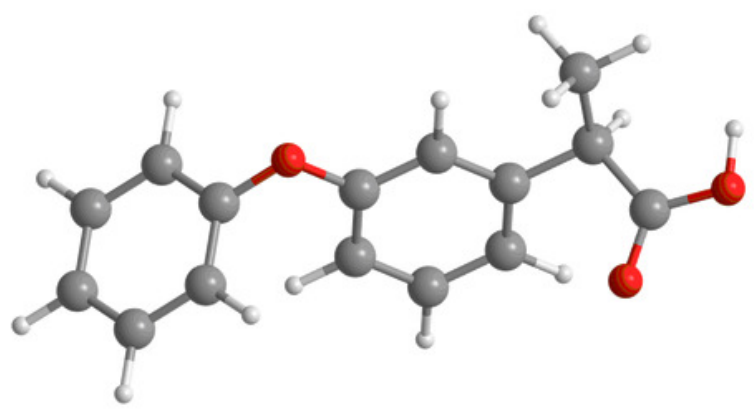

Fenoprofen $\left(\mathrm{pK}_{\mathrm{a}}=4.5\right)^{\mathrm{b}}$ 
Figure 2

The synthesis pathways of MSp-TDI-calix adsorbent

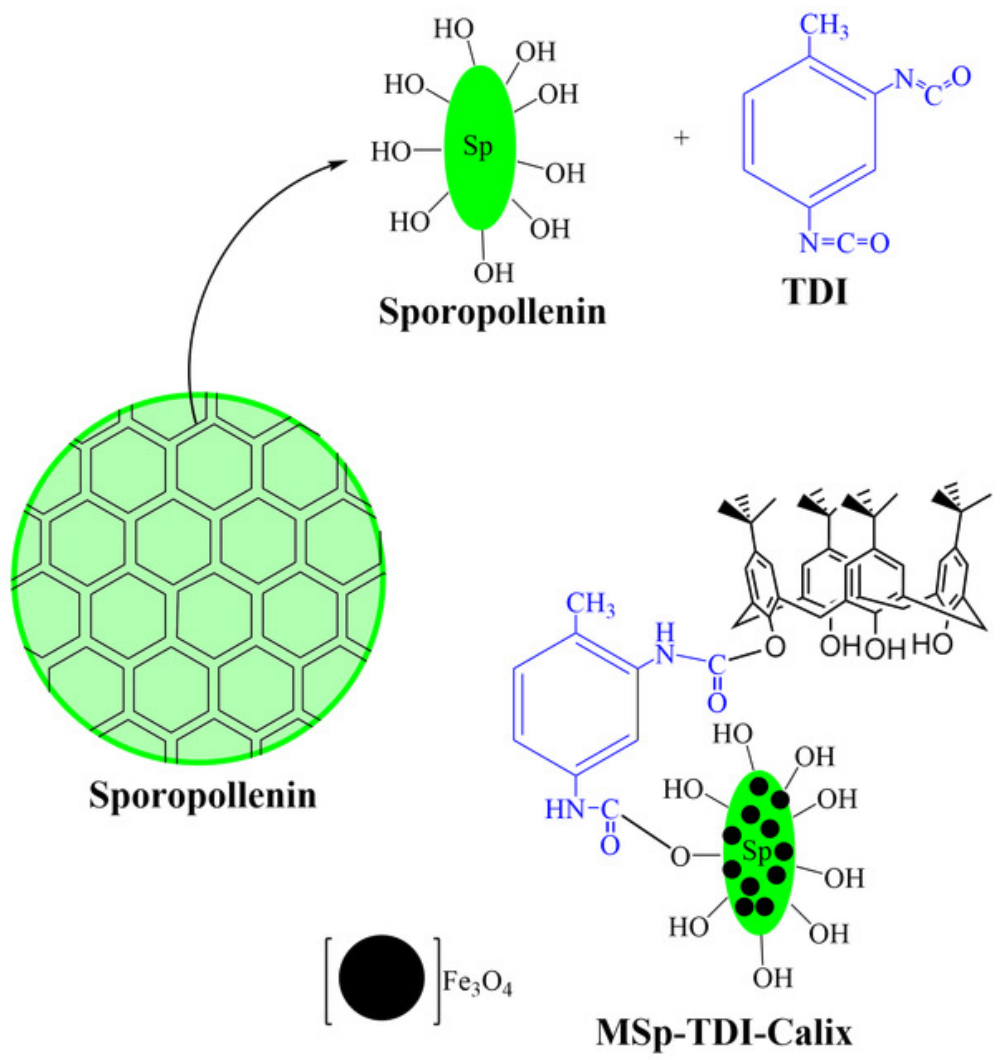

MSp-TDI-Calix $\underset{70{ }^{\circ} \mathrm{C}}{\stackrel{\text { Dry toluene, } \mathrm{N}_{2}}{\longrightarrow}}$

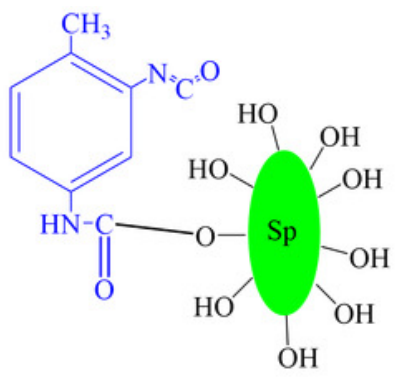

Sp-TDI

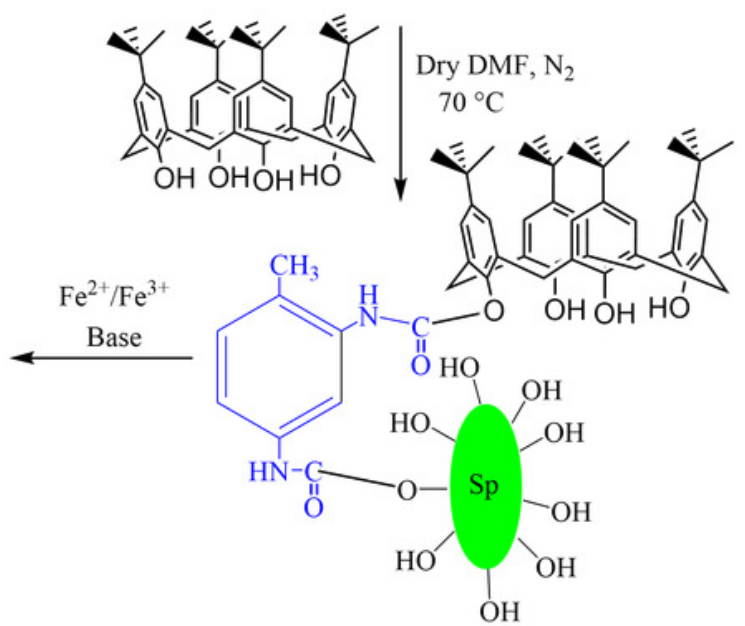

Sp-TDI-Calix 
Figure 3

FTIR spectra of synthesized adsorbent

FTIR spectra of (A) Sp-TDI, (B) Sp-TDI-calix and (C) MSp-TDI-calix

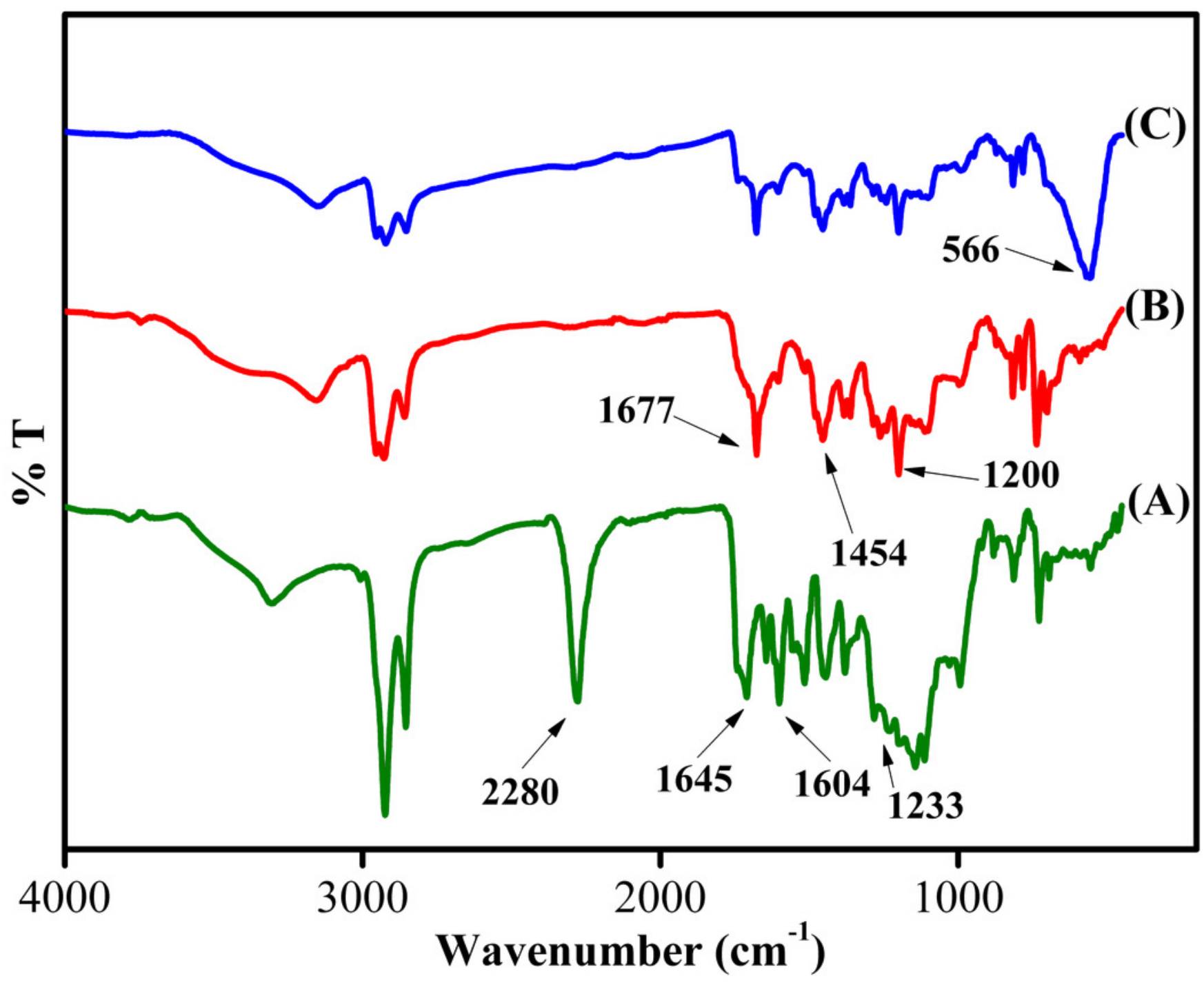


Figure 4

FESEM images of synthesized adsorbent

FESEM images of (A) sporopollenin, (B) Sp-TDI-calix and (C) MSp-TDI-calix
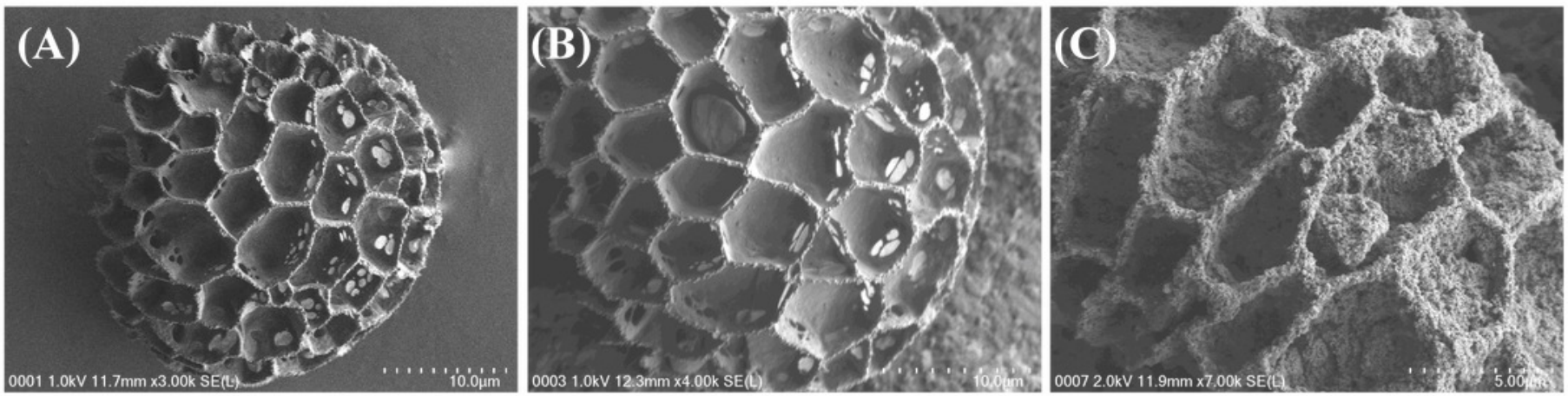
Figure 5

EDX spectra of synthesized adsorbent

EDX spectra of (A) Sp-TDI-calix and (B) MSp-TDI-calix

*Note: Auto Gamma Correction was used for the image. This only affects the reviewing manuscript. See original source image if needed for review.
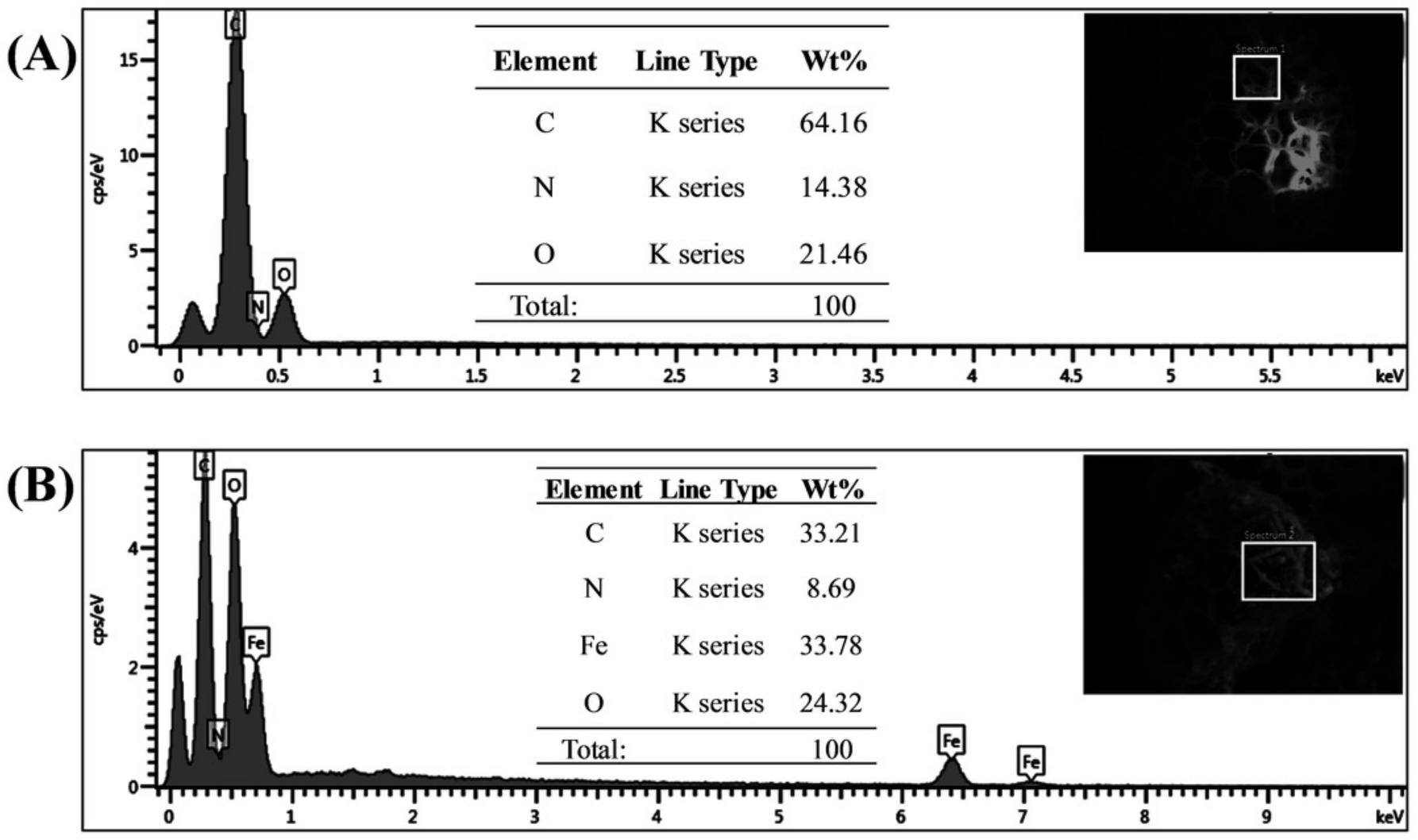


\section{Figure 6}

The effect of adsorbent dosage and sample volume

The effect of (A) adsorbent dosage, and (B) sample volume for the extraction of NSAIDs using MSp-TDI-calix and analysis using HPLC-DAD. HPLC conditions: acidified (1\% with acetic acid) water/acetonitrile $(50: 50 \mathrm{v} / \mathrm{v})$ as a mobile phase at a flow rate of $1 \mathrm{~mL} \mathrm{~min}{ }^{-1}$, the HPLC column temperature was set at $40{ }^{\circ} \mathrm{C}$, the sample injection volume was $10 \mu \mathrm{L}$, the DAD detection for the selected NSAIDs was carried out at multiple wavelengths i.e., 281, 255, 271 and $219 \mathrm{~nm}$ for INP, KTP, IBP and FNP respectively
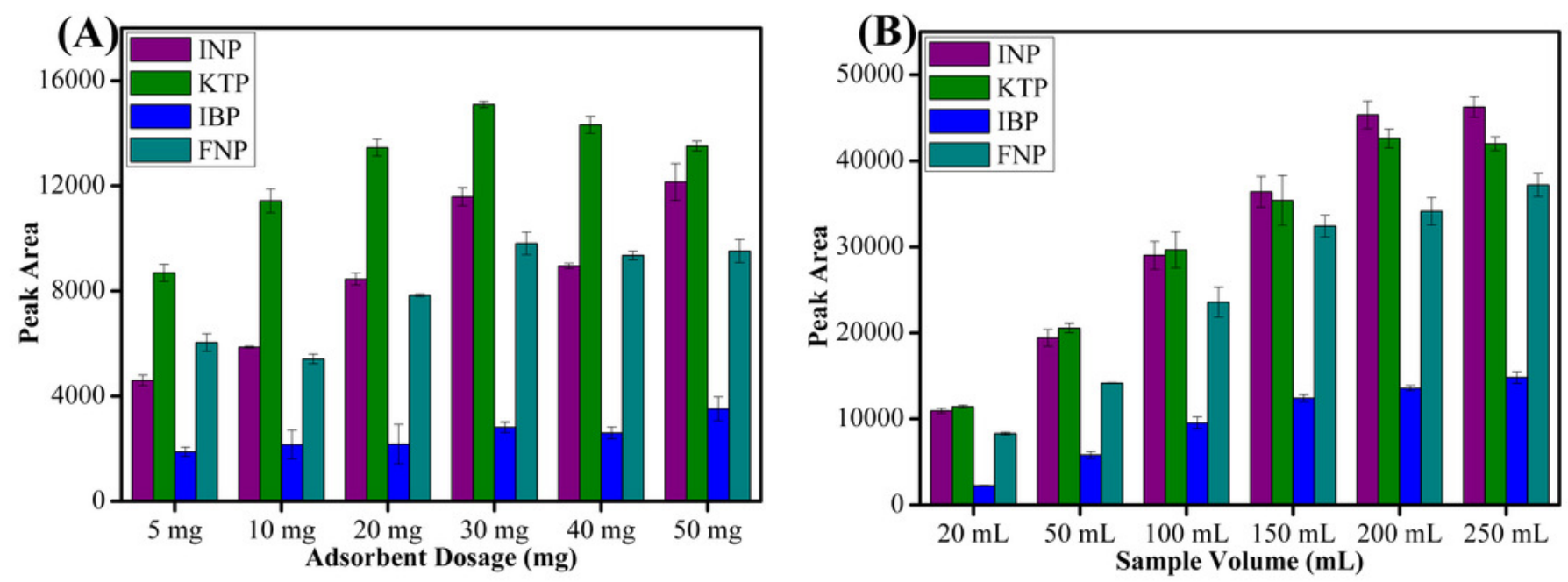


\section{Figure 7}

The effect of extraction time and desorption time

The effect of (A) extraction time, and (B) desorption time on the extraction of NSAIDs from 5

- 60 min using MSp-TDI-calix and analysis using HPLC-DAD. HPLC conditions: acidified (1\% with acetic acid) water/acetonitrile $(50: 50 \mathrm{v} / \mathrm{v})$ as a mobile phase at a flow rate of $1 \mathrm{~mL} \mathrm{~min}^{-1}$, the HPLC column temperature was set at $40^{\circ} \mathrm{C}$, the sample injection volume was $10 \mu \mathrm{L}$, the DAD detection for the selected NSAIDs was carried out at multiple wavelengths i.e., 281, 255, 271 and $219 \mathrm{~nm}$ for INP, KTP, IBP and FNP respectively
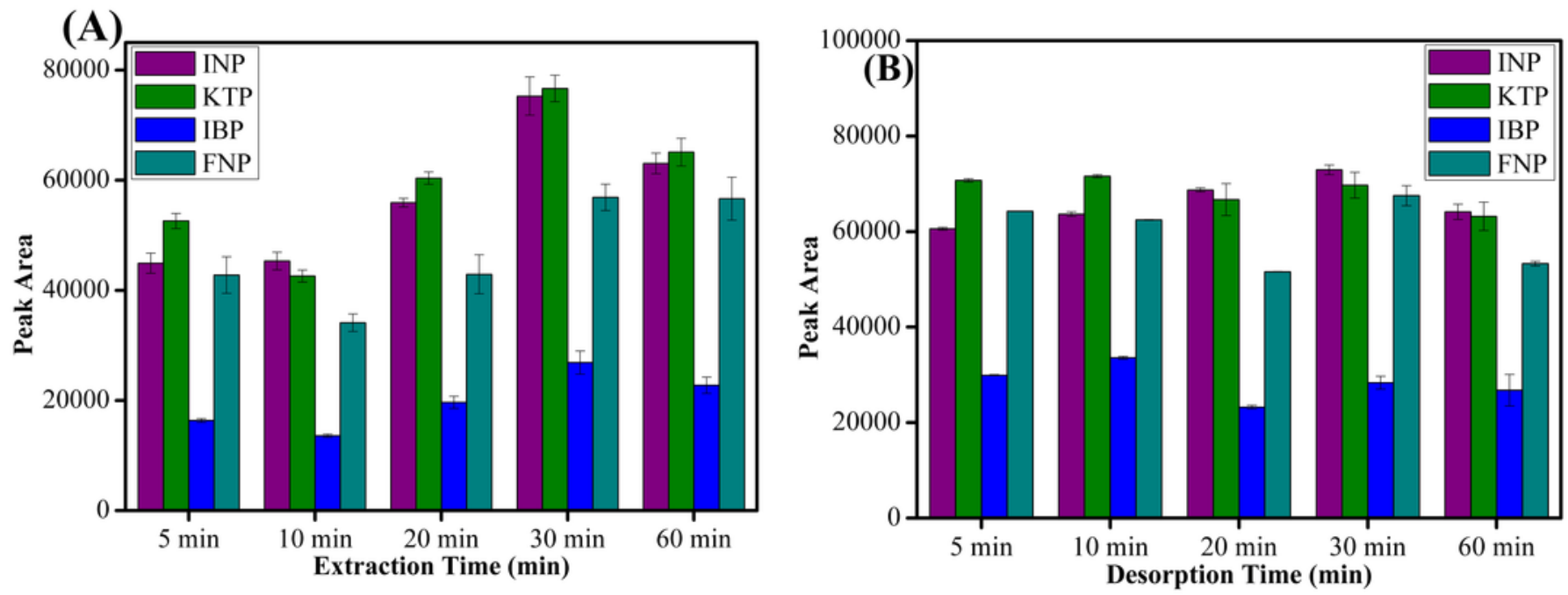


\section{Figure 8}

The effect of type of organic eluent and volume of organic eluent

The effect of (A) type of organic eluent, and (B) volume of organic eluent for the extraction of NSAIDs using MSp-TDI-calix and analysis using HPLC-DAD. HPLC conditions: acidified (1\% with acetic acid) water/acetonitrile (50:50 v/v) as a mobile phase at a flow rate of $1 \mathrm{~mL} \mathrm{~min}{ }^{-1}$, the HPLC column temperature was set at $40^{\circ} \mathrm{C}$, the sample injection volume was $10 \mu \mathrm{L}$, the DAD detection for the selected NSAIDs was carried out at multiple wavelengths i.e., 281, 255, 271 and $219 \mathrm{~nm}$ for INP, KTP, IBP and FNP respectively
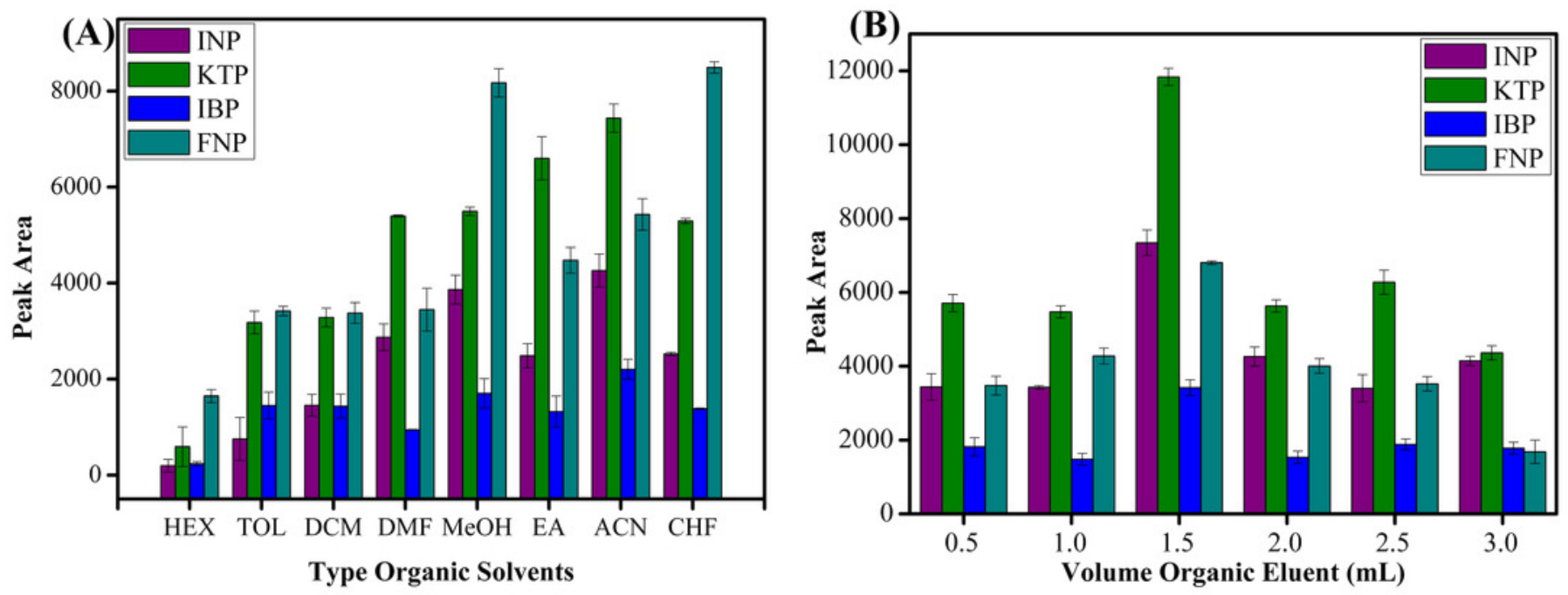


\section{Figure 9}

The effect of solution $\mathrm{pH}$

The effect of solution $\mathrm{pH}$ for the extraction of NSAIDs using MSp-TDI-calix and analysis using HPLC-DAD. HPLC conditions: acidified ( $1 \%$ with acetic acid) water/acetonitrile (50:50 v/v) as a mobile phase at a flow rate of $1 \mathrm{~mL} \mathrm{~min}-1$, the HPLC column temperature was set at $40{ }^{\circ} \mathrm{C}$, the sample injection volume was $10 \mu \mathrm{L}$, the DAD detection for the selected NSAIDs was carried out at multiple wavelengths i.e., 281, 255, 271 and $219 \mathrm{~nm}$ for INP, KTP, IBP and FNP respectively

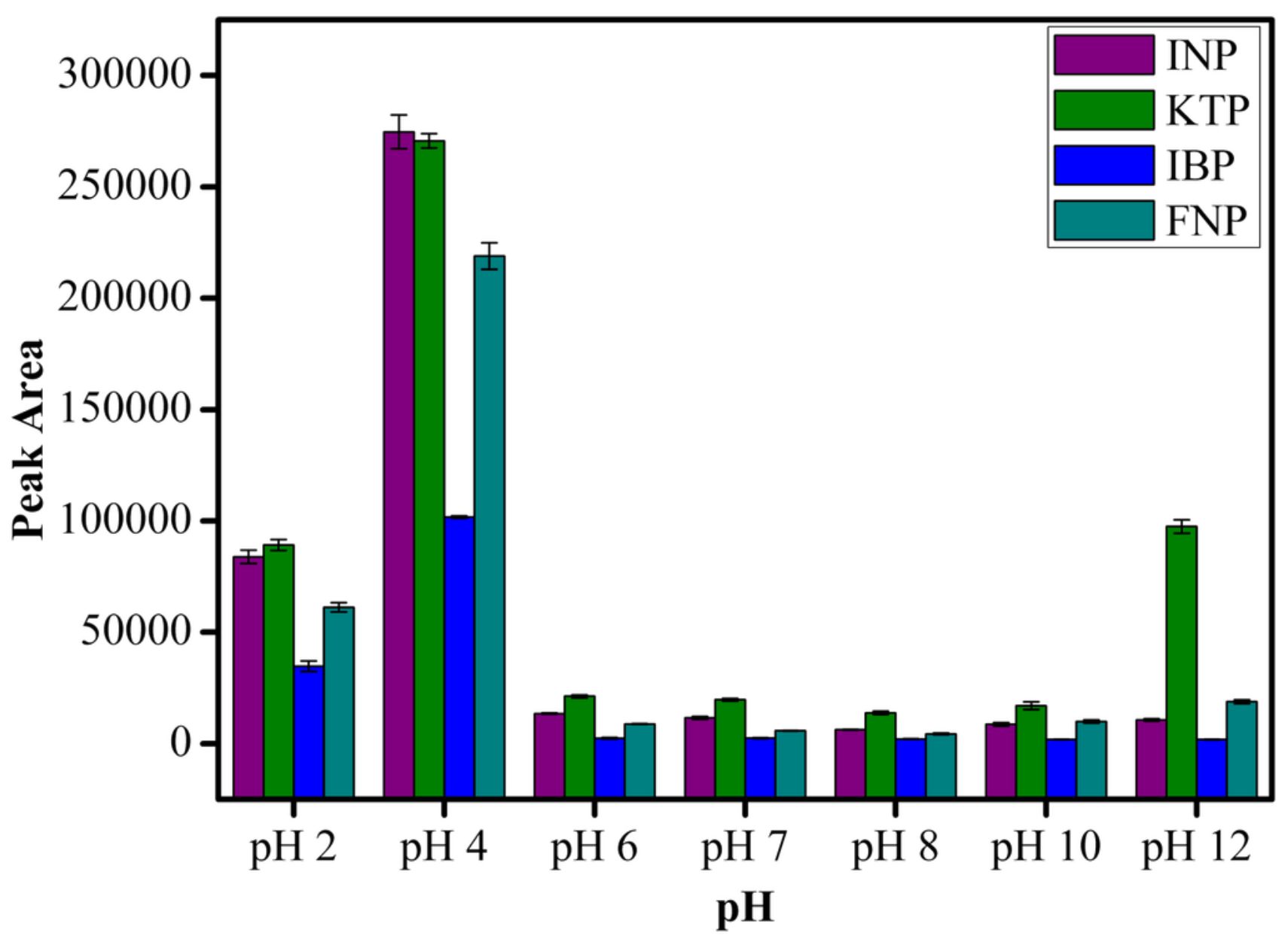


Figure 10

HPLC chromatograms of water samples

HPLC chromatograms of water samples (spiked with $100 \mathrm{ug} / \mathrm{L}$ of each NSAIDs) using the proposed MSp-TDI-calix MSPE method; (A)(i) non-spiked tap water; (A)(ii) spiked tap water; (B)(i) non-spiked drinking water; (B)(ii) spiked drinking water; (C)(i) non-spiked river water; (C)(ii) spiked river water. Peak identification: (1) INP, (2) KTP, (3) IBP, and (4) FNP

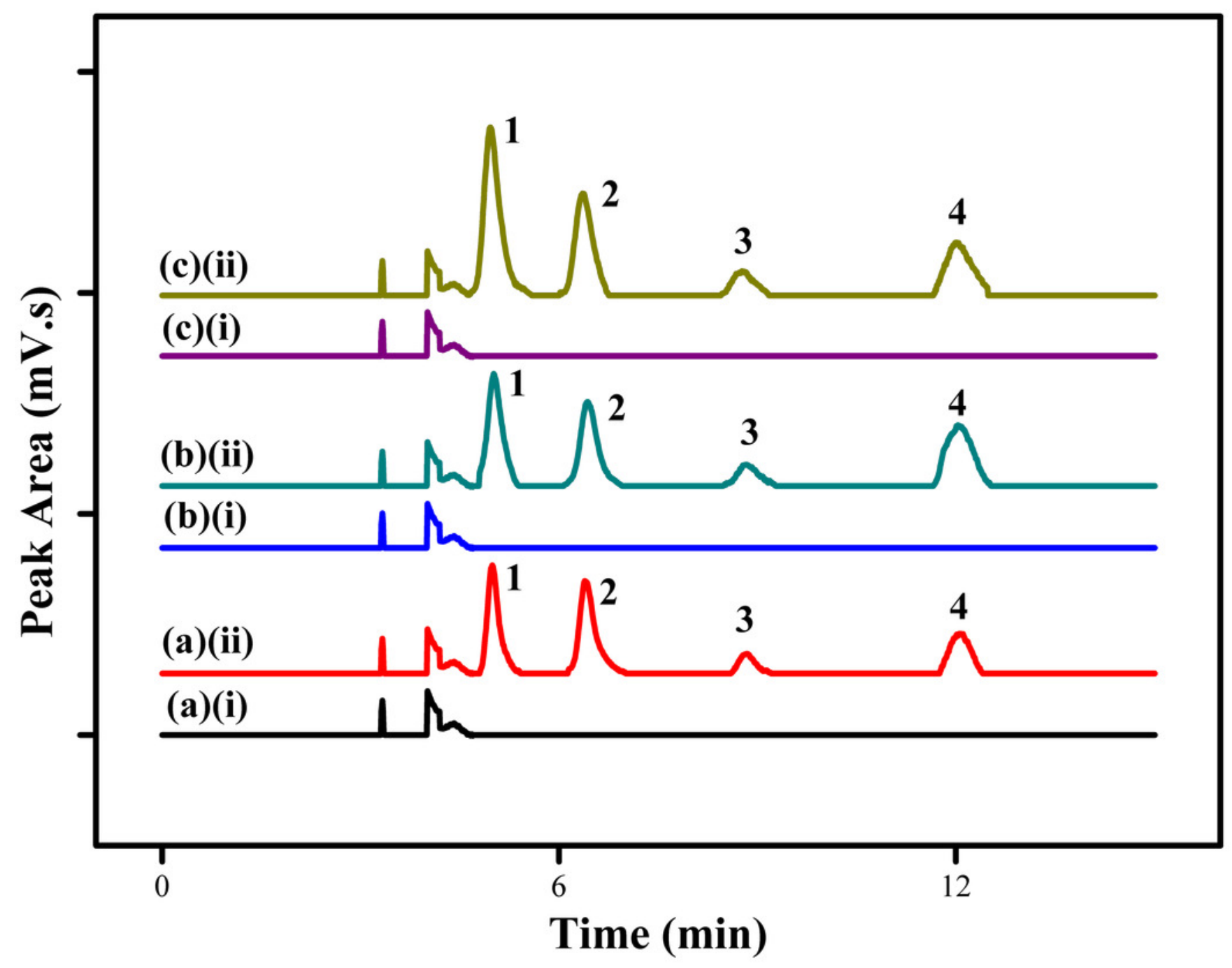




\section{Table $\mathbf{1}$ (on next page)}

Qualitative data of the proposed MSPE technique 


\begin{tabular}{|c|c|c|c|c|c|c|c|}
\hline \multirow[b]{2}{*}{ ANALYTE } & \multirow[b]{2}{*}{$\begin{array}{l}\text { LINEARITY } \\
(\mu \mathrm{g} / \mathrm{L})\end{array}$} & \multirow[b]{2}{*}{$\begin{array}{c}\text { REGRESSION } \\
\text { EQUATION }\end{array}$} & \multirow[b]{2}{*}{$R^{2}$} & \multirow[b]{2}{*}{$\begin{array}{c}\text { LOD } \\
(\mu \mathrm{g} / \mathrm{L})\end{array}$} & \multirow[b]{2}{*}{$\begin{array}{c}\text { LOQ } \\
(\mu \mathrm{g} / \mathrm{L})\end{array}$} & \multicolumn{2}{|c|}{ PRECISION } \\
\hline & & & & & & $\begin{array}{c}\text { INTRA } \\
(\text { RSD\% } \\
n=5)\end{array}$ & $\begin{array}{l}\text { INTER } \\
\text { (RSD\% } \\
n=15)\end{array}$ \\
\hline INP & $0.5-500$ & $\begin{array}{c}y=219677 x+ \\
3773\end{array}$ & 0.9930 & 0.074 & 0.25 & 2.4 & 2.5 \\
\hline KTP & $0.5-500$ & $\begin{array}{c}y=213367 x+ \\
4440\end{array}$ & 0.9916 & 0.061 & 0.20 & 3.2 & 2.8 \\
\hline IBP & $0.5-500$ & $\begin{array}{c}y=58351 x+ \\
851\end{array}$ & 0.9951 & 0.267 & 0.89 & 3.9 & 3.1 \\
\hline FNP & $0.5-500$ & $\begin{array}{c}y=170853 x+ \\
1283\end{array}$ & 0.9993 & 0.111 & 0.37 & 2.4 & 3.2 \\
\hline
\end{tabular}


Table 2 (on next page)

Percentage relative recovery and RSD $(n=5)$ of NSAIDs in spiked water samples extracted with MSp-TDI-calix 
1 Table 2 Percentage relative recovery and RSD $(n=5)$ of NSAIDs in spiked water samples 2 extracted with MSp-TDI-calix

\begin{tabular}{|c|c|c|c|c|c|c|c|}
\hline \multirow[t]{2}{*}{ Analyte } & \multirow[t]{2}{*}{$\begin{array}{l}\text { Spiked } \\
\text { (ng/mL) }\end{array}$} & \multicolumn{2}{|c|}{$\begin{array}{c}\text { Tap water } \\
(n=5)\end{array}$} & \multicolumn{2}{|c|}{$\begin{array}{l}\text { Drinking Water } \\
(n=5)\end{array}$} & \multicolumn{2}{|c|}{$\begin{array}{l}\text { River Water } \\
(n=5)\end{array}$} \\
\hline & & $\begin{array}{c}\text { Recovery } \\
(\%)\end{array}$ & $\begin{array}{l}\text { RSD } \\
(\%)\end{array}$ & $\begin{array}{c}\text { Recovery } \\
(\%)\end{array}$ & $\begin{array}{l}\text { RSD } \\
(\%)\end{array}$ & $\begin{array}{c}\text { Recovery } \\
\text { (\%) }\end{array}$ & $\begin{array}{l}\text { RSD } \\
(\%)\end{array}$ \\
\hline \multirow[t]{2}{*}{ INP } & 10 & 92.4 & 3.6 & 104.6 & 1.9 & 103.6 & 4.0 \\
\hline & 100 & 99.6 & 4.1 & 107.9 & 4.0 & 103.3 & 1.8 \\
\hline \multirow[t]{2}{*}{ KTP } & 10 & 88.1 & 2.1 & 107.8 & 2.1 & 98.2 & 2.2 \\
\hline & 100 & 97.4 & 1.6 & 105.7 & 4.6 & 106.5 & 3.2 \\
\hline \multirow[t]{2}{*}{ IBP } & 10 & 109.8 & 4.6 & 105.2 & 3.0 & 94.3 & 4.5 \\
\hline & 100 & 110.7 & 1.8 & 94.3 & 4.3 & 115.8 & 1.9 \\
\hline \multirow[t]{2}{*}{ FNP } & 10 & 103.5 & 4.4 & 96.2 & 2.6 & 97.2 & 3.5 \\
\hline & 100 & 103.2 & 4.3 & 91.9 & 3.6 & 107.0 & 3.2 \\
\hline
\end{tabular}




\section{Table 3 (on next page)}

Comparison of the current work to other reported MSPE techniques and sample matrices for determination of NSAIDs 
1 Table 3 Comparison of the current work to other reported MSPE techniques and sample matrices for 2 determination of NSAIDs

\begin{tabular}{|c|c|c|c|c|c|c|}
\hline Matrix & Adsorbent & Technique & $\begin{array}{c}\text { Linearity } \\
\text { range } \\
(\mathrm{ng} / \mathrm{mL})\end{array}$ & $\begin{array}{c}\text { Recovery } \\
(\%)\end{array}$ & $\begin{array}{c}\text { LODs } \\
(\mathrm{ng} / \mathrm{mL})\end{array}$ & Ref \\
\hline Blood & $\mathrm{Fe}_{3} \mathrm{O}_{4} @ \mathrm{SiO}_{2} @ \mathrm{IL}$ & $\begin{array}{c}\text { MSPE/HPLC } \\
\text { UV }\end{array}$ & $0.5-100$ & $92-97$ & $0.2-0.5$ & $\begin{array}{l}\text { (Amiri et } \\
\text { al., 2016) }\end{array}$ \\
\hline Water & $\begin{array}{c}\text { Metal organic } \\
\text { framework } \\
\mathrm{Fe}_{3} \mathrm{O}_{4} / \mathrm{MIL}- \\
101(\mathrm{Cr})\end{array}$ & $\begin{array}{c}\text { MSPE/UHPLC- } \\
\text { MS/MS }\end{array}$ & $0.1-25$ & NR & $\begin{array}{c}0.01- \\
0.19\end{array}$ & $\begin{array}{l}\text { (Wang et } \\
\text { al., 2017) }\end{array}$ \\
\hline $\begin{array}{c}\text { Water } \\
\text { and river } \\
\text { water }\end{array}$ & $\begin{array}{c}\mathrm{C}_{18} / \mathrm{Diol}-\mathrm{Fe}_{3} \mathrm{O}_{4} \\
\text { MNPs }\end{array}$ & $\begin{array}{c}\text { MSPE/HPLC } \\
\text { UV }\end{array}$ & $5-800$ & NR & $\begin{array}{c}0.42- \\
1.44\end{array}$ & $\begin{array}{c}\text { (Luo et al., } \\
2015)\end{array}$ \\
\hline $\begin{array}{l}\text { Urine } \\
\text { And } \\
\text { sewage }\end{array}$ & $\begin{array}{l}\text { MNPs modified } \\
\text { with } \\
\text { cetyltrimethyl- } \\
\text { ammonium } \\
\text { bromide (CTAB) }\end{array}$ & $\begin{array}{c}\text { MSPE/HPLC } \\
\text { DAD }\end{array}$ & $7-200$ & $91-97$ & $2-7$ & $\begin{array}{c}\text { (Khoeini } \\
\text { Sharifabadi } \\
\text { et al., } \\
\text { 2014) }\end{array}$ \\
\hline $\begin{array}{c}\text { Tap, } \\
\text { drinking } \\
\text { and } \\
\text { river } \\
\text { water }\end{array}$ & MSp-TDI-calix & $\begin{array}{c}\text { MSPE/HPLC } \\
\text { DAD }\end{array}$ & $5-500$ & $88-116$ & $\begin{array}{c}0.06- \\
0.26\end{array}$ & $\begin{array}{c}\text { Current } \\
\text { study }\end{array}$ \\
\hline
\end{tabular}

